\title{
The global middle-atmosphere aerosol model MAECHAM5-SAM2: comparison with satellite and in-situ observations
}

\author{
R. Hommel ${ }^{1, *}$, C. Timmreck ${ }^{1}$, and H. F. Graf ${ }^{2}$ \\ ${ }^{1}$ Max Planck Institute für Meteorologie, Hamburg, Germany \\ ${ }^{2}$ Centre for Atmospheric Science, Department of Geography, Cambridge University, Cambridge, UK \\ * now at: Centre for Atmospheric Science, Department of Chemistry, Cambridge University, Cambridge, UK
}

Received: 22 July 2010 - Published in Geosci. Model Dev. Discuss.: 1 September 2010

Revised: 27 June 2011 - Accepted: 15 July 2011 - Published: 16 September 2011

\begin{abstract}
In this paper we investigate results from a three-dimensional middle-atmosphere aerosol-climate model which has been developed to study the evolution of stratospheric aerosols. Here we focus on the stratospheric background period and evaluate several key quantities of the global distribution of stratospheric aerosols and their precursors with observations and other model studies. It is shown that the model fairly well reproduces in situ observations of the aerosol size and number concentrations in the upper troposphere and lower stratosphere (UT/LS). Compared to measurements from the limb-sounding SAGE II satellite instrument, modelled integrated aerosol quantities are more biased the lower the moment of the aerosol population is. Both findings are consistent with earlier work analysing the quality of SAGE II retrieved e.g. aerosol surface area densities in the volcanically unperturbed stratosphere (SPARC/ASAP, 2006; Thomason et al., 2008; Wurl et al., 2010).
\end{abstract}

The model suggests that new particles are formed over large areas of the LS, albeit nucleation rates in the upper troposphere are at least one order of magnitude larger than those in the stratosphere. Hence, we suggest that both, tropospheric sulphate aerosols and particles formed in situ in the LS are maintaining the stability of the stratospheric aerosol layer in the absence of direct stratospheric emissions from volcanoes. Particle size distributions are clearly bimodal, except in the upper branches of the stratospheric aerosol layer where aerosols evaporate. Modelled concentrations of condensation nuclei $(\mathrm{CN})$ are smaller than measured in regions of the aerosol layer where aerosol mixing ratios are largest. This points to an overestimated particle growth by coagulation.

Transport regimes of tropical stratospheric aerosol have been identified from modelled aerosol mixing ratios and

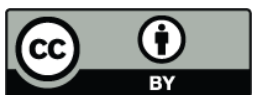

Correspondence to: R. Hommel (rene.hommel@zmaw.de) correspond to those deduced from satellite extinction measurements. We found that convective updraft in the Asian Monsoon region significantly contributes to both stratospheric aerosol load and size. The timing of formation and descend of layers of fine mode particles in the winter and spring polar stratosphere ( $\mathrm{CN}$ layer) are well reproduced by the model. Where temperatures in the stratosphere increase with altitude, nucleation is unlikely to occur. Nevertheless, in these regions we find a significant concentration of fine mode aerosols. The place of origin of these particles is in the polar stratosphere. They are mixed into the mid-latitudes by planetary waves. There enhanced condensation rates of sulphuric acid vapour counteract evaporation and extend aerosol lifetime in the upper branches of the stratospheric aerosol layer.

Measured aerosol precursors concentrations, $\mathrm{SO}_{2}$ and sulphuric acid vapour, are fairly well reproduced by the model throughout the stratosphere.

\section{Introduction}

It has long been recognised that aerosols are an important constituent of the stratosphere (SPARC/ASAP, 2006; IPCC, 2007). Observations show that hydrophilic (soluble) sulphate droplets are the major constituent of the particulate matter above the tropopause. Nitric acid, organics, or meteor debris influence the composition on synoptic scales (e.g. Sheridan et al., 1994; Deshler et al., 2003b; Gerding et al., 2003; Baumgardner et al., 2004; Froyd et al., 2009). Stratospheric aerosols serve as cooling agent by scattering incoming solar radiation (Lacis et al., 1992; IPCC, 2007). They interact with catalytic cycles of stratospheric ozone depletion providing surfaces for heterogeneous reactions (e.g. Angell et al., 1985; Borrmann et al., 1997) and play a vital role in the formation of polar stratospheric clouds and cirrus clouds (Tolbert, 1994; DeMott et al., 2003). Stratospheric aerosol climate interactions become obvious when violent volcanic

Published by Copernicus Publications on behalf of the European Geosciences Union. 
eruptions emit large amounts of aerosol precursors directly into the stratosphere (reviewed in Robock, 2000). In recent years much attention has been paid to ideas to counteract human-induced global warming due to enhanced greenhouse gas concentrations and to mitigate climate change by means of artificially increased stratospheric albedo (e.g. Crutzen, 2006; Rasch et al., 2008; Heckendorn et al., 2009).

However, the climate response to stratospheric aerosols is not yet understood well enough. Model studies of climate impacts from tropical volcanic eruptions with stratospheric injection heights often diverge in the dynamical responses of the climate system. So the strengthening of the positive phase of the Northern Atlantic Oscillation and the associated "winter warming" phenomenon as observed after the eruptions of Mt. Pinatubo or El Chichón is only tentatively being reproduced (Stenchikov et al., 2002, 2006). Also responses within the stratosphere, like the positive temperature anomalies in the tropics, are often not well captured by models (Thomas et al., 2009). Model studies of the dynamics of aerosols and its climate impacts in a stratosphere not perturbed by volcanic material (the "background" state of the stratosphere) significantly differ in aerosol key quantities. While model estimates of the total sulphur load of the stratosphere are in good agreement with observations (Kent and McCormick, 1984; Pitari et al., 2002; Takigawa et al., 2002), conversion rates of microphysical and chemical processes with respect to stratospheric aerosol formation and depletion significantly differ between models. The same is true for aerosol transport cycles which are associated with the model's ability to reproduce main features of atmospheric circulation (convective updraft, stratospheretroposphere exchange, the Brewer-Dobson circulation, and the quasi-biennial oscillation in the equatorial stratosphere). Transport processes to a large degree determine the life cycle of stratospheric aerosols (Trepte and Hitchman, 1992; Hitchman et al., 1994; Holton et al., 1995; Hamill et al., 1997). Deficits are also seen in model representation of observed aerosol precursor abundances (Mills et al., 2005a; SPARC/ASAP, 2006), although the data base for these measurements is distinctly smaller than that for tropospheric observations (SPARC/ASAP, 2006), making an assessment difficult. The relevance of certain processes stabilising the stratospheric aerosol layer in volcanically quiescent periods, e.g. the partitioning between $\mathrm{SO}_{2}$ and gaseous $\mathrm{H}_{2} \mathrm{SO}_{4}$ in altitudes well above the aerosol layer, still is uncertain (Rinsland et al., 1995; Vaida et al., 2003; Mills et al., 2005a,b).

While during volcanically active episodes observations of stratospheric aerosol load, particle size, and effects on the surface climate largely agree over a range of observational methods, during volcanically quiescent periods a distinct inconsistency prevails in particular regarding the aerosol size and number density (Russell et al., 1996; Deshler et al., 2003a; SPARC/ASAP, 2006; Wurl et al., 2010). From in situ measurements it was derived that background aerosols usually have a median radius below $0.2 \mu \mathrm{m}$. In contrast, aerosols in the stratosphere perturbed from large tropical volcanic eruptions show median radii above $0.4 \mu \mathrm{m}$ (SPARC/ASAP, 2006). This impacts scattering of incoming solar radiation. Fine mode dominated background aerosol scatters less efficiently in the visible range than accumulation or coarse mode dominated volcanic aerosol. Consequently, remote sensing instruments, which are mostly designed to measure atmospheric particulate trace quantities in the visible and near infrared, are not able to accurately measure those aerosol populations that are dominated by fine mode particles. Their relative detection error exponentially increases for particles smaller than $0.1 \mu \mathrm{m}$ in radius; the retrieved size of $0.05 \mu \mathrm{m}$ aerosols from Sun-sky radiance measurements may be deemed to have a relative error of $50 \%$ (e.g. Dubovik et al., 2000).

In situ instruments, however, are able to measure the number of stratospheric aerosols down to $0.01 \mu \mathrm{m}$ with adequate accuracy (Deshler et al., 2003a) with uncertainties in the determination of the particle size of approximately $\pm 10 \%$.

To better assess climate relevant processes attributed to stratospheric aerosols by means of global climate models, it is necessary to accurately simulate their dynamics. This comprises modelling the formation and global dispersion of stratospheric aerosols considering also various tropospheric processes since soluble aerosol above the tropopause originates in one form or another from sources in the troposphere (SPARC/ASAP, 2006). Of particular importance for modelling aerosol-climate interaction is the prognostic treatment of particle size (e.g. Adams and Seinfeld, 2002; Zhang et al., 2002; Dusek et al., 2006). It has been shown that prescribing the size of aerosols in models predicting bulk aerosols (e.g. Takigawa et al., 2002; Rasch et al., 2008) instead of interactively predicting the shape of the size distribution (e.g. Timmreck, 2001; Adams and Seinfeld, 2002; Spracklen et al., 2005; Stier et al., 2005) systematically affects model predictions of aerosol, precursor transport and mixing as well as the interaction with chemical cycles in the atmosphere, and aerosol direct and indirect radiative forcing (e.g. Zhang et al., 2002; Myhre et al., 2004; Heckendorn et al., 2009). This effect will be relatively small when global aerosol dispersion is analysed in terms of an integrated global aerosol quantity (burden, aerosol optical depth or equivalent) and apparently large when analysed in terms of aerosol size quantities or aerosol concentration. Pan et al. (1998) showed that uncertainties in the prediction of the size of sulphate aerosols is one of the largest contributors to the general model uncertainty in assessments of the indirect aerosol effect on radiative forcing (IPCC, 2007).

Although the integration of comprehensive and interactive aerosol modules in fourth- and fifth-generation climate models significantly improved the understanding of complex climate influences of anthropogenic and natural aerosol (IPCC, 2007; Ghan and Schwartz, 2007), most of the models do not explicitly consider the formation and evolution of aerosols in the stratosphere. Instead, stratospheric aerosol 
processes are highly simplified. Direct effects of aerosol particles in the stratosphere are quantified from prescribed three-dimensional climatologies of integrated aerosol quantities, either treated offline by simulations with other models or derived from observations. Only a few three-dimensional models were developed interactively predicting stratospheric aerosol. Due to computational expenses particularly implied by the increase of the vertical resolution in those models, aerosol processes were constrained to bulk descriptions of the aerosol mass (e.g. Timmreck et al., 1999; Takigawa et al., 2002; Rasch et al., 2008). Size resolving aerosol schemes were utilised in the climate model studies of Timmreck (2001) and Pitari et al. (2002) investigating the dynamics of stratospheric background aerosol. Setting the top of the atmosphere (TOA) at $10 \mathrm{hPa}(\sim 33 \mathrm{~km})$ in the model of Timmreck (2001) yields differences to observations of meridional aerosol transport and associated effects. However, this model adequately reproduced the global dispersion of stratospheric aerosols. Hence, aerosol key quantities (surface area, effective radius) and aerosol size distributions in the Northern Hemisphere were in good agreement to observations. The model of Pitari et al. (2002) had a TOA at $0.04 \mathrm{hPa}(\sim 72 \mathrm{~km})$ and was interactively coupled to a chemistry model. Apart from reproducing the stratospheric aerosol layer, it successfully reproduced distinct features of the stratospheric composition, like the formation of an Antarctic ozone hole.

There exist few other size resolving aerosol codes coupled to one or two-dimensional middle-atmosphere dynamics models (Turco et al., 1979; Bekki and Pyle, 1992; Weisenstein et al., 1997). Some of them are interactively coupled to comprehensive chemistry schemes (Mills et al., 1999, 2005a,b). A model inter-comparison of these also including the three-dimensional models of Timmreck (2001) and Pitari et al. (2002) is found in the WMO/SPARC Assessment of Stratospheric Aerosol Properties (2006). The report revealed large differences in model representation of stratospheric aerosols and their precursors and demonstrated that reproducing observations of UT/LS aerosols in the volcanically perturbed as well as in the background stratosphere strongly depends on resolved transport processes in the models, also taking into account tropospheric processes.

In this paper we evaluate a three-dimensional model developed to study the dynamics of stratospheric aerosols in volcanically quiescent periods. The model deploys schemes for aerosol microphysics and sulphate chemistry to address the evolution of sulphate aerosols throughout the troposphere and stratosphere. Aerosols are size resolved and prognostic up to the TOA at $0.01 \mathrm{hPa}(\sim 80 \mathrm{~km})$. We compare several key quantities of the modelled aerosol layer with observations from the spaceborne SAGE II instrument, in situ measurements made in the northern hemispheric midlatitudes, and data from other models. Specific emphasis is on the evaluation of aerosol precursor abundances. A shortcoming of our model framework is the restriction of the aerosol composition to the binary system sulphate-water leading to an incomplete description of aerosol related processes in the troposphere. We will, however, show that, based on the current understanding of the processes forming aerosols in the stratosphere, our model framework is able to accurately reproduce the observed aerosol key quantities of surface area and number density. The latter, in particular, addresses the inconsistency found between integrated aerosol size quantities retrieved from SAGE II and in situ observations, which was highlighted in the WMO/SPARC Assessment of Stratospheric Aerosol Properties (2006). Furthermore, our results emphasise that the model approach of predicting the size of aerosols throughout the troposphere and stratosphere significantly improves the modelled global transport of aerosol in the stratosphere. In Sect. 2 model and experimental setups are described. In Sect. 3 we evaluate the model by diagnosing the sulphur budget, comparing precursors with published data from literature and observations. We evaluate integrated aerosol size parameters with two independent SAGE II climatologies based upon different retrieval algorithms. Finally we compare size distributions predicted by the model to in situ measured number densities in the midlatitudes of the Northern Hemisphere. A summary is given in Sect. 4. The interannual variability of the modelled stratospheric aerosol layer is subject for further analysis in a companion paper.

\section{Methods}

\subsection{Host model}

In this work, the aerosol-microphysical module SAM2 is implemented in the middle-atmosphere (MA) configuration of the three-dimensional atmospheric general circulation model (AGCM) ECHAM5. This AGCM was evaluated in several configurations $^{1}$. A detailed description of principal components is found in Roeckner et al. (2003). The middleatmosphere configuration MAECHAM5 has a vertical representation of the atmosphere up to $0.01 \mathrm{hPa}(\sim 80 \mathrm{~km})$ and comprises a parametrisation of the momentum flux deposition from vertically propagating gravity waves of tropospheric origin after Hines (1997). Details on the model configuration are given in Manzini et al. (2006). In the vertical, the model has $39 \sigma$-hybrid layers. The layer thickness in the UT/LS is $\sim 1.5 \mathrm{~km}$, further expanding to $\sim 2.5 \mathrm{~km}$ towards the top of the atmosphere. Prognostic variables are integrated with a spectral triangular truncation at wave number 42 (T42). Corresponding Gaussian grid cells, in which physical processes and non-linear terms are calculated, cover a horizontal area of $\sim 2.8^{\circ} \times 2.8^{\circ}$. The integration time step length is 15 minutes. As lower boundary conditions we are using climatological mean AMIP2 sea surface temperatures and sea ice concentrations. Prognostic aerosols are decoupled from the ECHAM5 radiation code

\footnotetext{
${ }^{1}$ see Special Section in Journal of Climate, 19(16), 3769-3987, 2006.
} 
(Fouquart and Bonnel, 1980; Mlawer et al., 1997), radiative transfer calculations were made every two hours, applying the Tanre et al. (1984) aerosol climatology. Prognostic chemical compounds are advected on a Gaussian grid every time step by applying a semi-Lagrangian transport scheme following Lin and Rood (1996).

\subsection{Aerosol module}

The aerosol microphysics module SAM2 is based on the size-segregated aerosol module SAM of Timmreck and Graf (2000). In its new formulation the module is not restricted to the stratosphere - it treats the formation and evolution of sulphuric acid-water $\left(\mathrm{H}_{2} \mathrm{SO} / \mathrm{H}_{2} \mathrm{O}\right)$ aerosol droplets throughout the atmosphere. The module considers the aerosol microphysical processes of binary homogenous nucleation, condensation and evaporation of sulphuric acid and water, as well as particle coagulation. Sulphuric acid droplets are assumed to be spherical and in thermodynamic equilibrium with the environment, which is a valid assumption for the relatively large time integration increments of a threedimensional AGCM (Hamill et al., 1977; Steele and Hamill, 1981). The microphysics module is valid in the temperature range between $195 \mathrm{~K}$ and $373 \mathrm{~K}$ and for relative humidities between $10 \%$ and $98 \%$. The sulphuric acid equilibrium concentration above a droplet is calculated from the vapour pressures of $\mathrm{H}_{2} \mathrm{SO}_{4}$ and $\mathrm{H}_{2} \mathrm{O}$, which are determined after Kulmala and Laaksonen (1990) and McDonald (1965). To calculate the vapour pressures of the two aerosol components, activity coefficients $a_{\mathrm{H}_{2} \mathrm{O}}$ and $a_{\mathrm{H}_{2} \mathrm{SO}_{4}}$ are read from a lookup table of pre-computed values according the formulation given by Giauque et al. (1960).

Following the fixed sectional approach (e.g. Gelbard et al., 1980), the microphysics module resolves the aerosol size from $1 \times 10^{-3} \mu \mathrm{m}$ to $\sim 2.6 \mu \mathrm{m}$ in 35 logarithmically spaced bins. The width of the bins is determined by mass doubling according to Kritz (1975). The interaction between aerosols and processes affecting the Earth's climate for several reasons depends on the size of aerosols. To assess size dependent aerosol properties, it makes sense to divide an aerosol population into subranges, independent on the numerical discretisation of the aerosols size spectrum. For diagnostic purposes the following subranges are defined: A nucleation mode where aerosols have radii $R_{p}$ smaller than $<0.005 \mu \mathrm{m}$, an Aitken mode $\left(0.005 \mu \mathrm{m} \leq R_{p}<0.05 \mu \mathrm{m}\right)$, an accumulation mode $\left(0.05 \mu \mathrm{m} \leq R_{p}<0.5 \mu \mathrm{m}\right)$ and a coarse mode $\left(R_{p} \geq 0.5 \mu \mathrm{m}\right)$.

In preceding studies of Timmreck (2001) on the evolution of stratospheric background aerosols, by using the predecessor module SAM coupled to a three-dimensional AGCM with a top of the atmosphere at $\sim 30 \mathrm{~km}$, only the total mass of sulphuric acid aerosol was predicted (bulk approach). Furthermore, in the troposphere below $300 \mathrm{hPa}$ the bulk sulfur cycle of Feichter et al. (1996) substituted the prognostic treatment of aerosol microphysics. In the new version of the module introduced here, the size of each discretised aerosol size section is predicted throughout the atmosphere and is advected as an atmospheric tracer.

New particle formation via binary homogeneous nucleation and the density of the binary mixture $\mathrm{H}_{2} \mathrm{SO}_{4} / \mathrm{H}_{2} \mathrm{O}$ are parametrised following Vehkamäki et al. (2002). This parametrisation is based on experimental data in the temperature range $230.15 \mathrm{~K}<T<305.15 \mathrm{~K}$ and for relative humidities of $0.01 \%<\mathrm{RH}<100 \%$. To be applicable in the cold stratospheric environment the authors extrapolated nucleation rates down to $190 \mathrm{~K}$. The number density of freshly formed particles with a size smaller than the lower bound are scaled into the smallest defined size section, thereby preserving the particle's net sulphur content.

Condensation of $\mathrm{H}_{2} \mathrm{SO}_{4}$ onto aerosols as well as the particle's partial evaporation are number conserving processes. In the microphysics module, sulphuric acid vapour mass transfer is treated as an advective process in radius space. Numerically this is expressed in a flux of size changing particles from one bin to an adjacent bin. To preserve aerosol number we applied a one-dimensional hybrid exponential-upwind advection scheme (Spalding, 1972; Chlond, 1994; Timmreck and Graf, 2000). The probability of molecules encountering a particle's surface and being absorbed, as expressed in the condensation equation (Seinfeld and Pandis, 1998) by mass accommodation coefficient $\alpha$, was set to be unity (i.e. total absorption). That is a suitable assumption for condensing sulphuric acid vapour in the cold stratospheric environment (Timmreck, 2001). Mass is conserved via a serially operating, non-iterative algorithm tracing size sections whose particles underwent large changes leading to unrealistic negative concentrations. Their appropriate mass is redistributed to size sections upstream of the filtered bins. While this introduces moderate numerical diffusion in terms of the prognostic mass mixing ratio in sub-ranges of the size distribution, the method avoids numerical dispersion, which is a common problem in many numerical formulations solving competing aerosol growth processes (e.g. Tsang and Brock, 1983). The scheme is simple in its implementation and further details are given in Hommel (2008). In comparison to other state-ofthe-art aerosol modules, Kokkola et al. (2009) showed that combining a number preserving one-dimensional advective type condensation scheme with a mass conserving filtering algorithm fairly well reproduces the growth particularly of ultra-fine particles under stratospheric background and moderately polluted conditions.

Another important growth process for fine mode aerosols and also a significant sink for the number of particles freshly formed from the gas phase is coagulation. In the microphysics module only Brownian coagulation is considered, since it dominates over other inter-particular collisional scavenging processes (Jacobson, 2005). The coagulation kernel is calculated according Fuchs (1964), accounting for noncontinuum effects after Cunningham (1910). Solving the linearised coagulation equation follows Timmreck and Graf 
(2000), who introduced a mass conserving formulation of the semi-implicit method of Toon et al. (1988). To limit the computational expense in solving the coagulation problem, various aerosol size predicting microphysics codes attempt to exclude coagulation of certain particle size regimes (e.g. Stier et al., 2005; Kokkola et al., 2008). For instance, from theory it can be shown that the production term due to coagulation is small compared to the sink term due to coagulation and is also orders of magnitude smaller than the production term due to condensation (Dal Maso et al., 2002). The efficiency of particles to coalesce with particles from the opposite end of the size spectrum is larger than that for approximately equally sized particles. However, in the stratosphere coagulation kernels (describing the rate at which particles of one size coagulate with particles of another size) are distinctly smaller than in the troposphere or in the planetary boundary layer. The coagulation efficiency between particle regimes linearly scales with the particle's mean free path length in the atmosphere depending on particle size. In SAM2 particles of all sizes are allowed to collide and coalesce leading to higher computational cost, but considerably improving the quality of the simulations (Kerminen et al., 2004).

The modularised integration of SAM2 into its host model provides access to non-microphysical aerosol sources and sinks which were defined for ECHAM5's standard aerosol module HAM (Stier et al., 2005). Processes of sedimentation, dry and wet deposition are described in Stier et al. (2005) and were adapted to resolve the aerosol size by fixed sections instead of log-normal functions. Global surface emissions of natural and anthropogenic sulphur are taken from the AeroCom database, scenario B (present day scenario) and represent year 2000 conditions (Dentener et al., 2006). Like in ECHAM5-HAM $2.5 \%$ of the total emitted sulphur is treated as direct emission of primary particulate sulphate. Emissions of primary sulphate from shipping and industry are partitioned between the accumulation and coarse modes of the aerosol size distribution. Other primary particulate sulphate emissions are attributed to the Aitken and accumulation mode. The treatment of tropospheric volcanic emissions also follows AeroCom scenario B. Non-eruptive $\mathrm{SO}_{2}$ emissions are taken from Andres and Kasgnoc (1998) and are distributed to model levels between volcano height and one third below. Eruptive $\mathrm{SO}_{2}$ emissions were taken from Halmer et al. (2002) and are distributed to model levels $500 \mathrm{~m}$ to $1500 \mathrm{~m}$ above the volcano height. Our study focuses on the stratospheric background period after 1995, so any stratospheric injections of large volcanic eruptions are not considered. The flux of dimethyl sulphide (DMS) from the marine biosphere is calculated as in Kloster et al. (2006) from prescribed monthly mean DMS sea water concentrations according to Kettle and Andreae (2000). Terrestrial biogenic DMS fluxes are prescribed based on monthly means (Pham et al., 1995).

The mixing ratio of carbonylsulphide (OCS) in the atmosphere is prescribed based on climatological monthly means taken from a transient run of ECHAM4-SAM, which was interactively coupled to the chemical transport model CHEM. In this simulation OCS emissions were held constant, yielding a surface mixing ratio of $520 \mathrm{pptv}$ (SPARC/ASAP, 2006).

\subsection{Chemistry module}

The chemistry module employs the sulphur cycle of Feichter et al. (1996) in regions of the atmosphere below the tropopause and a scheme based on a sulphur chemistry extension of the chemical transport model CHEM (Steil et al., 2003) in model levels at the tropopause and above. The tropospheric sulphur cycle takes into account the aqueous phase transformation of $\mathrm{SO}_{2}$ into sulphate in stratiform and convective clouds as well as homogeneous reactions of day and night time oxidation of DMS and $\mathrm{SO}_{2}$. Oxidants and, in the stratosphere, photolysis rates are prescribed based on zonal and monthly mean data sets. In the troposphere, concentrations of $\mathrm{OH}, \mathrm{H}_{2} \mathrm{O}_{2}, \mathrm{NO}_{2}$ and $\mathrm{O}_{3}$ are taken from a climatology of the chemistry transport model (CTM) MOZART2 (Horowitz et al., 2003). In the stratosphere, $\mathrm{OH}, \mathrm{NO}_{2}$, and $\mathrm{O}_{3}$ concentrations as well as photolysis rates of OCS, $\mathrm{SO}_{2}$, $\mathrm{SO}_{3}$, and $\mathrm{O}_{3}$ originate form a climatology of the chemistry climate model MESSy (Jöckel et al., 2005). The rate of $\mathrm{H}_{2} \mathrm{SO}_{4}$ photolysis in the UV range was estimated according Turco et al. (1979) and Rinsland et al. (1995) based on the MESSy calculated photolysis rate of $\mathrm{HCl}$. Since photolysis rates are generally prescribed in this study, we are not able to examine recently proposed mechanisms of upper atmospheric $\mathrm{H}_{2} \mathrm{SO}_{4}$ degradation through photolysis by visible and near-infrared solar radiation as proposed by Vaida et al. (2003). Reactions and reaction rates are listed in Table 1.

Compared to the model's predecessor ECHAM4-SAM (Timmreck, 2001), now the $\mathrm{SO}_{2}$ forming bimolecular reaction between $\mathrm{SO}$ and the $\mathrm{NO}_{2}$ is taken into account. Because in the stratosphere the $\mathrm{NO}_{2}$ mixing ratio is largest at altitudes a few kilometres above the main stratospheric aerosol layer (see e.g. Gordley, 1996), and according to JPL/NASA (2003) the rate of this reaction does not depend on the atmospheric temperature, significant differences in the prediction of stratospheric precursor abundance between the predecessor and our current model are likely.

\subsection{Observational data}

The model is evaluated with satellite-measured integral aerosol quantities, size resolved in situ aerosol measurements and precursor observations from several campaigns. Our analysis focusses on the validation of the aerosol size dependent integral quantities surface area density (SAD), volume density (VD), and effective radius $\left(R_{\text {eff }}\right)$. The satellite data sets described below may contain other information as well, which are not considered here due to their higher retrieval uncertainties. We also do not take into account the SPARC ASAP/CCMVal stratospheric aerosol 
Table 1. Reactions and reaction rate coefficients of stratospheric sulphur chemistry in MAECHAM5-SAM2. Intermediate reactions bypassed where products are given in brackets. Reaction rate constants after JPL/NASA (2003).

\begin{tabular}{|c|c|c|}
\hline \multicolumn{3}{|c|}{ Homogeneous reactions in the stratosphere } \\
\hline Reaction & & Reaction rate $\left(\mathrm{cm}^{-3} \mathrm{~s}^{-1}\right)$ \\
\hline $\mathrm{SO}+\mathrm{O}_{2}$ & $\mathrm{SO}_{2}+\mathrm{O}$ & $R_{2}=2.6 \times 10^{-13} e^{-2400 / T}$ \\
\hline $\mathrm{SO}+\mathrm{O}_{3}$ & $\mathrm{SO}_{2}+\mathrm{O}_{2}$ & $R_{8}=2.6 \times 10^{-13} e^{-2400 / T}$ \\
\hline $\mathrm{SO}+\mathrm{NO}_{2}$ & $\rightarrow \quad \mathrm{SO}_{2}+\mathrm{NO}$ & $R_{1}=1.4 \times 10^{-11}$ \\
\hline $\mathrm{SO}_{2}+\mathrm{O}$ & $\rightarrow \quad \mathrm{SO}_{3}$ & $R_{10}=f\left(K_{0}\right), \quad K_{0}=1.3 \times 10^{-33}(T / 300)^{-3.6}$ \\
\hline $\mathrm{SO}_{2}+\mathrm{O}_{3}$ & $\rightarrow \quad \mathrm{SO}_{3}+\mathrm{O}_{2}$ & $R_{9}=3.0 \times 10^{-12} e^{-7000 / T}$ \\
\hline $\mathrm{SO}_{2}+\mathrm{OH}$ & $\rightarrow \quad \mathrm{HOSO}_{2}$ & $\begin{array}{l}R_{5}=f\left(K_{0}, K_{\infty}\right), K_{0}=3.0 \times 10^{-31}(T / 300)^{-3.3}, \\
K_{\infty}=1.5 \times 10^{-12}\end{array}$ \\
\hline $\mathrm{SO}_{3}+\mathrm{H}_{2} \mathrm{O}$ & $\rightarrow \quad\left(\mathrm{H}_{2} \mathrm{SO}_{4}\right)$ & $R_{7}=2.26 \times 10^{-43} \times T \times e^{6544 / T} \times \mathrm{H}_{2} \mathrm{O}$ \\
\hline $\mathrm{HOSO}_{2}+\mathrm{O}_{2}$ & $\rightarrow \quad \mathrm{SO}_{3}+\mathrm{HO}_{2}$ & $R_{6}=1.3 \times 10^{-12} e^{-330 / T}$ \\
\hline $\mathrm{OCS}+\mathrm{O}$ & $\rightarrow \mathrm{SO}+\mathrm{CO}$ & $R_{3}=2.1 \times 10^{-11} e^{-2200 / T}$ \\
\hline $\mathrm{OCS}+\mathrm{OH}$ & $\rightarrow \quad\left(\mathrm{SO}_{2}+\mathrm{CO}_{2}\right)$ & $R_{4}=1.1 \times 10^{-13} e^{-1200 / T}$ \\
\hline \multicolumn{3}{|l|}{$\begin{array}{l}\text { Photolysis } \\
\text { Reaction }\end{array}$} \\
\hline $\mathrm{OCS}+h v$ & $\rightarrow \quad \mathrm{CO}+\mathrm{S}$ & \\
\hline $\mathrm{H}_{2} \mathrm{SO}_{4}+h v$ & $\rightarrow \quad \mathrm{SO}_{3}+\mathrm{H}_{2} \mathrm{O}$ & \\
\hline $\mathrm{SO}_{2}+h v$ & $\rightarrow \quad \mathrm{SO}+\mathrm{O}$ & \\
\hline $\mathrm{SO}_{3}+h v$ & $\rightarrow \quad \mathrm{SO}_{2}+\mathrm{O}$ & \\
\hline$O_{3}+h v$ & $\rightarrow \quad \mathrm{O}_{2}+\mathrm{O}$ & \\
\hline
\end{tabular}

climatology (SPARC/ASAP, 2006, http://www.pa.op.dlr.de/ CCMVal/Forcings/CCMVal_Forcings_WMO2010.html) because this product is robust only for aerosol surface densities.

In this paper, integrated aerosol quantities are compared to stratospheric aerosol climatologies provided by the University of Oxford (PARTS, 2004; Wurl et al., 2010), hereinafter referred to as UOX, and the NASA AMES Laboratory (Bauman et al., 2003a,b), hereinafter referred to as AMES. The data sets give information about the integrated parameters surface area density, volume density, effective radius, total concentration as well as the size distribution geometric radius and distribution width.

In both data sets aerosol size parameters are retrieved from extinction profiles measured with a sun occultation instrument during the Stratospheric Aerosol and Gas Experiments (SAGE) II, aboard the ERBS satellite (McCormick, 1987). The instrument operated from October 1984 to August 2005, providing the longest record of global stratospheric aerosol so far. The latitudinal coverage of the measurements is approximately $70^{\circ} \mathrm{S}$ to $70^{\circ} \mathrm{N}$. In the vertical, the data were processed in $0.5 \mathrm{~km}$ intervals. The AMES climatology only considers data from $2 \mathrm{~km}$ above the tropopause. In the UOX solution all those extinction profiles were taken into account that passed a quality screening. Thus, the UOX climatology provides data at and potentially also below the tropopause. Since the AMES climatology ends in August 1999, our comparison between model and SAGE II is based on the year 1998, which is representative for the stratospheric background after the volcanic eruption of Mt. Pinatubo in 1991 (Deshler et al., 2006; SPARC/ASAP, 2006).

The AMES climatology combines the four wavelength extinction measurements from SAGEII with extinction profiles at $12.82 \mu \mathrm{m}$ from the Cryogenic Limb Array Etalon Spectrometer (CLAES; Roche et al., 1993), which, in particular, has advantages in the detection of volcanic aerosol. The algorithm retrieves the effective radius, surface area, volume density, and the width of a uni- or bimodal log-normal size distribution by examining satellite-measured extinction ratios to pre-computed values utilising a look-up table in combination with a parameter search technique. Complex refractive indices were precomputed at $215 \mathrm{~K}$ and for a constant 3 ppmv stratospheric water vapour content; the corresponding weight percentage of $\mathrm{H}_{2} \mathrm{SO}_{4}$ in the particles is $70.85 \%$. As Bauman et al. (2003b) showed, in the volcanically quiescent stratosphere AMES retrieved aerosol surface area is a few percent larger than in the climatology of Thomason et al. (1997) which was based on Principal Component Analysis (PCA; Thomason et al., 1997; Steele et al., 1999).

In the UOX climatogy an inversion technique is applied based on the Bayesian Optimal Estimation (BOE) theory. Details on the method are given in Wurl et al. (2010). The BOE approach combines a priori knowledge of measured particle size distributions (Deshler et al., 2003a) with spectral aerosol extinction measurements. That makes the BOE solution sensitive to fine mode particles (see Kent et al., 1995; 
Steele et al., 1999). A further strength of the BOE method are error estimates as part of the retrieval process. In contrast, other inversion techniques, like PCA, lead to solutions with a systematic bias (Steele et al., 1999). Wurl et al. (2010) showed that the BOE method is applicable in the presence of large experimental noise, making it superior to retrieve the size of background aerosols. BOE retrieved surface areas and volume densities are 20 to $50 \%$ larger than PCA solutions of the operational NASA SAGE II retrieval and are less biased to data inferred from in situ observations.

To compute the aerosol acidity and refractive indices, Wurl et al. (2010) deployed temperature and pressure observations from the National Meteorological Center (NMC) in combination with water vapour consistently measured by SAGE II.

The retrieved uncertainty estimates in the AMES data set are $20 \%$ for SAD and VD, and $18 \%$ for $R_{\text {eff. }}$ UOX uncertainty estimates are in the order of $23 \%$ for SAD, $12 \%$ for VD, and $13 \%$ for $R_{\text {eff }}$.

In situ measurements of aerosol quantities are inferred from optical particle counter (OPC) measurements in the stratosphere over Laramie (Wyoming, $41.3^{\circ} \mathrm{N}, 105.7^{\circ} \mathrm{W}$ ). To date the Laramie record is the most coherent in situ observation (see SPARC/ASAP, 2006, and references therein). The instrument, operative since 1971, measured stratospheric particle number concentrations at $R \geq 0.15$ and $0.25 \mu \mathrm{m}$. In 1989 the instrumentation was redesigned, now being able to resolve aerosol spectra in 12 channels from $\geq 0.15$ to $2.0 \mu \mathrm{m}$. A condensation nuclei $(\mathrm{CN})$ counter simultaneously measures particles with a radius of $10 \mathrm{~nm} \pm 10 \%$. Further details on the instrumentation and error estimates of derived aerosol quantities are given in Deshler et al. (2003a).

The modelled abundance of $\mathrm{SO}_{2}$ and gaseous $\mathrm{H}_{2} \mathrm{SO}_{4}$ are compared with data from literature. In addition, the modelled abundance of $\mathrm{SO}_{2}$ is compared to measurements taken during the Stratospheric Aerosol and Gas Experiment (SAGE) III Ozone Loss and Validation Experiment (SOLVE), conducted from December 1999 to March 2000 (e.g. Lee et al., 2003). $\mathrm{SO}_{2}$ was measured by a chemical ionisation mass spectrometer (CIMS; Hunton, 2000) onboard the NASA research aircraft DC-8. The detection limit was approximately 25 pptv. The flights were made in the Arctic high latitudes and occasionally also in the mid-latitudes at altitudes between 9 and $13 \mathrm{~km}$. SOLVE data were obtained from NASA's ESPO archive (http://espoarchive.nasa.gov/archive). Of the $\sim 11000$ samples for $\mathrm{SO}_{2}$, approximately only one fifth were made below the tropopause and are not considered in our analysis. The data include samples from the volcanic plume of the Icelandic volcano Hekla, which erupted on 26 February 2000. In the morning of the 28th, the research aircraft passed the plume in a transit flight from Edwards AFB to Kiruna, Sweden, and also several days later volcanic signals are apparent (Rose et al., 2003).

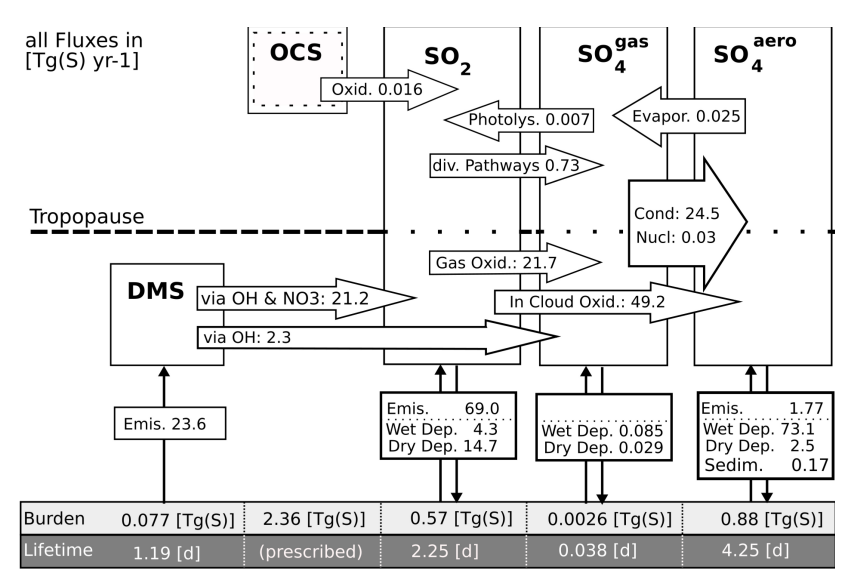

Fig. 1. Schematic budget diagnostics of model prognostic sulphur constituents in the last year of integration. All fluxes are expressed as $\operatorname{Tg}(\mathrm{S}) \mathrm{yr}^{-1}$, vertically integrated global mean column masses (burdens) as $\operatorname{Tg}(\mathrm{S})$, and whole atmosphere lifetimes as days.

\subsection{Experiment setup}

The model was integrated for $17 \mathrm{yr}$, starting in January 1990. To shorten the model's spin-up period, prognostic aerosol components were initialised from a zonally averaged aerosol mass mixing ratio which was derived from the climatological mean volume density of the UOX SAGE II climatology. We assumed that the aerosols are homogeneously composed of $75 \%$ sulphuric acid with a density of $1.7 \mathrm{~g} \mathrm{~cm}^{-3}$ throughout the stratosphere. The total mixing ratio was distributed over the size sections assuming an unimodal size distribution following Pinnick et al. (1976) with a mode radius of $0.0725 \mu \mathrm{m}$ and a standard deviation of 1.86. Prognostic sulphate precursors were not initialised. Instead, the atmospheric abundance of DMS, $\mathrm{SO}_{2}$ and $\mathrm{H}_{2} \mathrm{SO}_{4}$ is formed from boundary layer fluxes during the model integration.

Prescribing an initial aerosol load rather than synthesising the development over time of precursor and aerosol abundances in the stratosphere from surface emission might be problematic. However, Hommel (2008) showed in detail that all diagnosed parameters of the aerosol microphysics module are balanced from year six of the integration. We use the following eleven years as the base for the model climatology.

\section{Results and discussion}

\subsection{Global budgets}

In this section we evaluate modelled sulphur constituents for the whole atmosphere. Whenever possible, we will refer to individual rates of processes or values valid in either the troposphere or the stratosphere. Figure 1 shows a schematic diagram of the global budget of prognostic sulphur constituents based on annual means of the last year of the integration. 
Budgets of particular years do not differ at pre-decimal positions, since we integrated the model with climatological mean lower boundary conditions and the model's set up does not consider dominant interannual modes of stratospheric variability (QBO, solar cycle). In Fig. 1, atmospheric lifetimes are given as global residence times. As noted before, DMS oxidation is constrained to the troposphere and OCS mixing ratios are prescribed. In the budget analysis special consideration is given to ECHAM5's standard aerosol module HAM (Stier et al., 2005; Kloster et al., 2006) since both models use identical tropospheric process parametrisations and surface emission flux strengths. Hence, apparent differences in conversion rates diagnosed from both models are directly attributed to aerosol module specific treatments of aerosol dynamics and the explicit consideration of aerosols in the stratosphere in MACHAM5-SAM2.

With the explicit consideration of aerosol processes in the stratosphere, both the calculated global mean burden of sulphate aerosol and the lifetime are $\sim 17 \%$ larger than in ECHAM5-HAM. Nevertheless, the values are in the range of predictions from other global models, where aerosol processes are more or less constrained to the troposphere (Table 2). In the stratosphere Takigawa et al. (2002) diagnose an annual mean burden of sulphate aerosol of $0.149 \mathrm{Tg}(\mathrm{S})$ from the CCSR/NIES aerosol coupled middle-atmosphere AGCM. This corresponds well with $0.148 \mathrm{Tg}(\mathrm{S})$ derived in this study (17\% of the total aerosol burden). However, the global annual mean burden of sulphate aerosol in Takigawa et al. (2002) with $0.36 \mathrm{Tg}(\mathrm{S})$ is $60 \%$ smaller than in our simulation. Besides of a different handling of source strengths, potentially the neglected tropospheric aqueous phase chemistry in the CCSR/NIES model accounts for this distinct discrepancy. Aqueous phase chemistry converts approximately two thirds of the emitted $\mathrm{SO}_{2}$ to sulphate (Chin et al., 1996; SPARC/ASAP, 2006). Pitari et al. (2002) model a $2 \%$ higher stratospheric aerosol burden $(0.151 \mathrm{Tg}(\mathrm{S}))$ in a hybrid AGCM/CTM, resolving the size of sulphate aerosol by a sectional method with 15 bins. They refer to an estimated stratospheric aerosol burden of $0.156 \mathrm{Tg}(\mathrm{S})$ based on SAGE I/SAM II data (Kent and McCormick, 1984) from $2 \mathrm{~km}$ above the tropopause for the year 1979, a year in which the stratosphere was near background after the volcanic eruption of Fuego in 1975. Weisenstein et al. (1997) diagnose prognostic sulphur compounds and their transformation rates in the two-dimensional model AER also following a sectional approach. In the standard set-up with 40 bins they resolve the aerosol size range from $3.9 \times 10^{-4} \mu \mathrm{m}$ to $3.2 \mu \mathrm{m}$. Dependent on parametrisations of tropospheric processes AER predicts a stratospheric aerosol burden ranging from 0.08 to $0.221 \mathrm{Tg}(\mathrm{S})$, with lower numbers calculated without additionally imposed fluxes of $\mathrm{SO}_{2}$ and sulphate particles from the troposphere to the stratosphere. This comparison shows a very good agreement of MAECHAM5-SAM2 simulations both with observations and other model simulations.
Table 2. Comparison of sulphate aerosol burden and lifetimes from this and other climate model studies.

\begin{tabular}{lll}
\hline & $\begin{array}{l}\text { Burden } \\
(\mathrm{Tg}(\mathrm{s}))\end{array}$ & $\begin{array}{l}\text { Lifetime } \\
(\mathrm{d})\end{array}$ \\
\hline MAECHAM5-SAM2 & 0.88 & 4.25 \\
Stier et al. (2005)* $^{*}$ & 0.8 & 3.9 \\
Kloster et al. (2006) $^{*}$ & 0.73 & 3.42 \\
Feichter et al. (1996) $^{* *}$ & 0.57 & 4.3 \\
Barth et al. (2000) $_{\text {Easter et al. (2004) }}$ & 0.57 & 3.8 \\
Liu et al. (2005) & 1.07 & 6.8 \\
\hline
\end{tabular}

* ECHAM5-HAM

** ECHAM4 incl. tropospheric sulphur cycle

MAECHAM5-SAM2 model predicted deposition rates of sulphur compounds differ not more than $10 \%$ from ECHAM5-HAM, but the flux of sedimenting particles is a factor of two weaker in our model. An overestimation of sedimentation rates from modal aerosol modules was also highlighted by Weisenstein et al. (2007) in a two-dimensional model intercomparison study for stratospheric conditions. The MAECHAM5-SAM2 aqueous phase production of sulphate in tropospheric clouds is $6 \%$ larger than in ECHAM5HAM and accounts for $65 \%$ of the total global sulphate production, which is in the ballpark of other studies (e.g. Pham et al., 1995; Penner et al., 2001; Liu et al., 2005). Relative to the transformation rates of the two-dimensional model AER (SPARC/ASAP, 2006), in our simulation the stratospheric $\mathrm{SO}_{2}$ oxidation is one order of magnitude larger. Differences in the three-body reaction oxidising $\mathrm{SO}_{2}$ by the hydroxyl radical OH (see Weisenstein et al., 1997) may explain this relatively large discrepancy between both models.

In altitudes where $\mathrm{H}_{2} \mathrm{SO}_{4}$ is supersaturated, the residence time of sulphuric acid vapour is considerably shorter than that of $\mathrm{SO}_{2}$. In our simulation a three times longer lifetime of gaseous $\mathrm{H}_{2} \mathrm{SO}_{4}$ is predicted than diagnosed from ECHAM5HAM (Stier et al., 2005; Kloster et al., 2006). This is clearly attributed to the extended vertical representation of the atmosphere in the AGCM MAECHAM5, because, as shown later in Sect. 3.2, above $30 \mathrm{~km}$ (which is the TOA in the in the studies performed with ECAHM5-HAM) the mixing ratio of gaseous $\mathrm{H}_{2} \mathrm{SO}_{4}$ is several orders of magnitude larger than below. In our simulation $98 \%$ of the global total sulphuric acid vapour condenses onto existing particles, only $0.1 \%$ nucleates and the remaining part deposits in the planetary boundary layer. Compared to ECHAM5-HAM, the mass transfer of $\mathrm{H}_{2} \mathrm{SO}_{4}$ from the gas to the particle phase via new particle formation is 3.6 times weaker in our model. This is due to differences in the sequential processing of competing aerosol microphysics processes. By investigating box model versions of the modules HAM and SAM2, Kokkola et al. (2009) showed that the sequential processing of HAM is more robust with respect to steep gradients in the oxidation 
rate of $\mathrm{SO}_{2}$, e.g. as found in volcanic plumes. In the stratospheric background, however, predicted aerosol size distributions from both modules are almost indistinguishable in the accumulation and coarse mode. Also the size of fine particles $(R<0.01 \mu \mathrm{m})$ is better represented in SAM2 than in HAM compared to a benchmark model. In Kokkola et al. (2009) the latter was a hybrid kinetic-sectional module (Kazil et al., 2007) with an approximately three times finer resolved aerosol size range compared to SAM2. A potential method to further improve the treatment of the two processes condensation and nucleation, which compete for the available sulphuric acid vapour, is given in Hommel and Graf (2010). In this study it was shown that reserving a certain fraction of the available sulphuric acid vapour for nucleation significantly improves SAM2's ability to capture particle growth under elevated levels of $\mathrm{SO}_{2}$ in the stratosphere.

Interestingly, the simulated rate of evaporating sulphates in the stratosphere is almost twice as strong as the oxidation rate of OCS, which is suggested to stabilise stratospheric aerosol abundances above $25 \mathrm{~km}$ (SPARC/ASAP, 2006). Depending on its set up, the 2-D model AER predicts OCS oxidation fluxes from $0.032 \mathrm{Tg}(\mathrm{S}) \mathrm{yr}^{-1}$ (SPARC/ASAP, 2006) to $0.049 \mathrm{Tg}(\mathrm{S}) \mathrm{yr}^{-1}$ (Weisenstein et al., 1997). For the 3-D CCRS/NIES model Takigawa et al. (2002) diagnose $0.036 \mathrm{Tg}(\mathrm{S}) \mathrm{yr}^{-1}$. Our modelled OCS oxidation rate is less than half than that in the other models. This seems to be caused by the offline treatment and superimposing of OCS mixing ratios with photolysis rates taken from another model simulation (see also Sect. 3.2).

Photolysis of sulphuric acid vapour above $35 \mathrm{~km}$ is a major nonvolcanic pathway for the $\mathrm{SO}_{2}$ abundance in the upper stratosphere and mesosphere (discussed in Sect. 3.2). In our study, $7 \times 10^{-3} \mathrm{Tg}(\mathrm{S}) \mathrm{yr}^{-1}$ of the gaseous $\mathrm{H}_{2} \mathrm{SO}_{4}$ in the stratosphere is photolysed to $\mathrm{SO}_{2}$. This is only $1 \%$ of the total $\mathrm{SO}_{2}$ oxidised to sulphuric acid vapour above the tropopause.

\subsection{Aerosol precursor gases}

In this section we compare results of the simulated abundance of the prognostic sulphate aerosol precursors $\mathrm{SO}_{2}$ and sulphuric acid vapour against several observations and comparable model studies. We will concentrate on $\mathrm{SO}_{2}$ and gaseous $\mathrm{H}_{2} \mathrm{SO}_{4}$. DMS concentrations in the LS are several orders of magnitude lower than in the troposphere, and hence approximately negligible (Weisenstein et al., 1997). Prescribed fields are used for OCS.

During several field campaigns sulphur-bearing gases were measured in the troposphere, but they were measured only sporadically in the stratosphere (reviewed in SPARC/ASAP, 2006). Early in situ observations of $\mathrm{SO}_{2}$ (Meixner, 1984; Möhler and Arnold, 1992) and sulphuric acid vapour (Arnold and Fabian, 1980; Viggiano and Arnold, 1981; Arnold et al., 1981; Heitmann and Arnold, 1983; Arnold and Qiu, 1984; Schlager and Arnold, 1987; Möhler and Arnold, 1992; Reiner and Arnold, 1997) were conducted in the middle and upper stratosphere of $\mathrm{NH}$ mid-latitudes, some of them during volcanically active periods, e.g. during the eruption of El Chichon in 1982. Rinsland et al. (1995) reported $\mathrm{SO}_{2}$ profiles in the middle stratosphere provided by the ATMOS infrared spectrometer onboard the NASA Space Shuttle for SPACELAB 3 in 1985. After the massive eruption of the Philippine volcano Mt. Pinatubo in June 1991, a series of flight campaigns measured the abundance of several gases, including $\mathrm{SO}_{2}$ (SPARC/ASAP, 2006). In contrast to the above mentioned early in situ measurements, both spatial coverage and temporal resolution of airborne sampling techniques increased, but their altitudinal coverage is still often limited to the free troposphere. With respect to newer airborne observations, we choose to validate the modelled abundance of $\mathrm{SO}_{2}$ with previously unpublished measurements made during the NASA SAGE III Ozone Loss and Validation Experiment (SOLVE), conducted at high Arctic latitudes from December 1999 to March 2000. The majority of the data collected in 14 missions were sampled above the tropopause up to $13 \mathrm{~km}$ altitude.

In Fig. 2 a composite of calculated vertical profiles at the equator, the $\mathrm{NH}$ mid and high latitudes of all sulphur constituents is shown. In Fig. 3 we compare our model results to other models and specific in situ observations of stratospheric $\mathrm{SO}_{2}$ and sulphuric acid vapour, and in Fig. 4 we evaluate $\mathrm{LS} \mathrm{SO}_{2}$ mixing ratios with data collected during SOLVE. Compared to available measurements and appropriate model data, MAECHAM5-SAM2 reproduces distinct features in the atmospheric distribution of $\mathrm{SO}_{2}$ and gaseous $\mathrm{H}_{2} \mathrm{SO}_{4}$. In the lower stratosphere the rapid and effective photochemical transformation of $\mathrm{SO}_{2}$ to $\mathrm{H}_{2} \mathrm{SO}_{4}$ and the subsequent transfer of the latter into aerosol droplets results in the formation of distinct minima in the vertical profiles of both gases, whereas the aerosol mixing ratio increases (Fig. 2). In central and upper regions of the aerosol layer, between 20 and $35 \mathrm{~km}$, photodissociation of OCS increases the stratospheric $\mathrm{SO}_{2}$ abundance. In this region of the stratosphere, the positive gradient of $\mathrm{H}_{2} \mathrm{SO}_{4}$ gas mixing ratios is more pronounced than that of $\mathrm{SO}_{2}$. Due to the positive gradient in the stratospheric temperature above the cold point tropopause, both the oxidation rate of $\mathrm{SO}_{2}$ and the $\mathrm{H}_{2} \mathrm{SO}_{4}$ vapour pressure increase with altitude. The latter is anticorrelated with the condensation sink of $\mathrm{H}_{2} \mathrm{SO}_{4}$ on aerosols. Hence, the positive gradient of the stratospheric sulphuric acid vapour mixing ratio is more pronounced than the gradient in $\mathrm{SO}_{2}$ between $\sim 20$ and $35 \mathrm{~km}$. When $\mathrm{H}_{2} \mathrm{SO}_{4}$ is subsaturated, aerosols evaporate completely. This results in a strong negative gradient in the aerosol mixing ratio above $30 \mathrm{~km}$ (Fig. 2). Between 37 and $40 \mathrm{~km}, \mathrm{H}_{2} \mathrm{SO}_{4}$ released into the gas phase reaches peak mixing ratios of $\sim 70 \mathrm{pptv}$. Slightly lower values are found in mid and high latitudes. Above $40 \mathrm{~km}$, sulphuric acid vapour is photolysed to $\mathrm{SO}_{3}$, which in turn rapidly photolyses to $\mathrm{SO}_{2}$ (Burkholder and McKeen, 1997), ultimately forming a reservoir of $\mathrm{SO}_{2}$ in the stratosphere above $40 \mathrm{~km}$. 

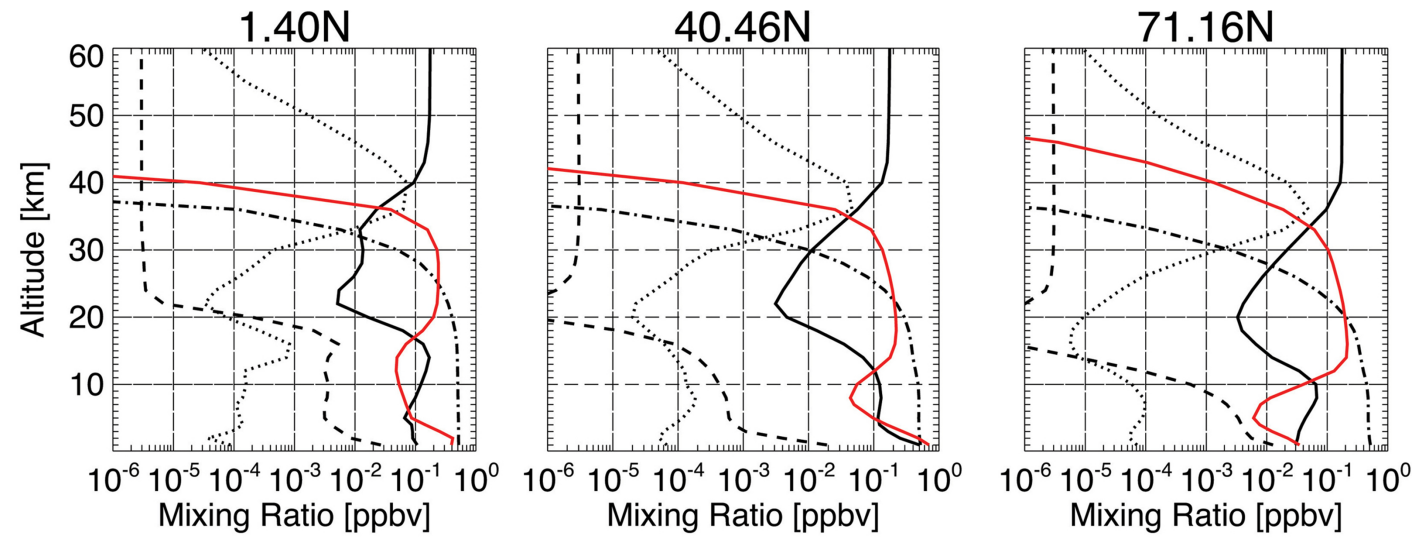

$\mathrm{SO} 2$

SO4 (Gas) - - D DMS

-..- OCS (prescr.)

Aerosol

Fig. 2. Calculated vertical profiles of modelled sulphur constituents in the Northern Hemisphere. Shown here are climatological zonal means of the $11 \mathrm{yr}$ analysis period from 1996 to 2006.

Measurements by the ATMOS infrared spectrograph onboard the NASA Space Shuttle for SPACELAB 3, made from April to May 1985 between $26^{\circ}$ and $32^{\circ} \mathrm{N}$, confirm the formation of such a $\mathrm{SO}_{2}$ reservoir (Fig. 3). However, the data also revealed a negative gradient in the $\mathrm{SO}_{2}$ mixing ratio around the stratopause (Rinsland et al., 1995). This gradient cannot be reproduced in our simulation. Instead, the $\mathrm{SO}_{2}$ mixing ratio remains approximately constant in heights above $48 \mathrm{~km}$. Whether this is due to an unresolved mechanism in the modelled photochemistry or due to a missing sink in the microphysics, e.g. vapour uptake by meteor debris (e.g. Mills et al., 2005a; Turco et al., 1981), remains speculative since neither of the processes postulated in the literature is confirmed experimentally.

In the LS simulated $\mathrm{SO}_{2}$ mixing ratios are in good agreement with observations made during SOLVE between December 1999 and March 2000 (Fig. 4). SOLVE data are affected by the eruption of the Icelandic volcano Hekla on 26 February 2000 (Rose et al., 2003). However, in our analysis volcanic samples were not excluded from the data. Our statistical analysis revealed that the signal of the UT/LS background concentration of $\mathrm{SO}_{2}$ is robust in the data set and showing a well pronounced normal distribution at all altitudes: the median of the measured background concentration in the LS with $35 \mathrm{pptv}(0.25$ and 0.75 percentiles at 28.3 and 43.3 pptv) is $20 \%$ below the analysis of Lee et al. (2003), which excluded data above 200 pptv and considered also samples made in the UT. In Fig. 4, outliers (represented by larger spread of the data as well as mean values lying beyond the interquartile range, IQR, of the data) are clearly marking measurements affected by volcanic $\mathrm{SO}_{2}$. The simulated $\mathrm{SO}_{2}$ is more biased relative to SOLVE in the lower latitudes. At $46^{\circ} \mathrm{N}$, between 10 and $11 \mathrm{~km}$, MAECHAM5SAM2 overpredicts the mixing ratio by $58 \%$ in DJF and by $150 \%$ in MAM. In higher latitudes most of the model data are at least within the IQR of the observations.
A detailed investigation of how sulphate aerosol models predict stratospheric $\mathrm{SO}_{2}$ mixing ratios in the tropics and subtropics was given in SPARC/ASAP (2006). With minor exceptions due to the different treatment of chemical and physical processes in the models, the predicted profiles are in qualitative agreement. The spread of the data, however, is rather large between the models. Some of the models are also distinctly different from the ATMOS observations (Rinsland et al., 1995) in the middle and upper stratosphere. As seen in the Figs. 2 and 3 our model does not predict a distinct maximum in the (sub)tropical $\mathrm{SO}_{2}$ mixing ratio around $28 \mathrm{~km}$ altitude, which was more pronounced in the model results shown in SPARC/ASAP (2006) and Mills et al. (2005a).

For $\mathrm{SO}_{2}$ the Mills et al. (2005a) model clearly underestimates the ATMOS observations (Fig. 3a) whereas sulphuric acid vapour is within the range of observations above $28 \mathrm{~km}$ (Fig. 3b). Below, where aerosol concentrations are largest, Mills et al. (2005a) clearly over-estimates gaseous $\mathrm{H}_{2} \mathrm{SO}_{4}$ by more than $50 \%$. MAECHAM5-SAM2 is in agreement with the observations (Fig. 3b). Note, however, the spread of the measurements for the near-background prePinatubo period, which is larger than one order of magnitude above $28 \mathrm{~km}$.

Vertical profiles of $\mathrm{SO}_{2}$ in the tropics as predicted by the two-dimensional model AER (Weisenstein et al., 1997) exhibit vertical displacements of the altitudes of maxima and minima compared to our simulation. The displacements prevail in the extratropics and are in the order of $-6 \mathrm{~km}$, relative to our data, from above the tropopause to heights of $\sim 35 \mathrm{~km}$. The profiles for sulphuric acid vapour are in qualitative agreement between model and observations. In the tropics AER shows $\sim 50 \%$ larger values than our model but in the $\mathrm{NH}$ mid-latitudes the bias is marginal up to $32 \mathrm{~km}$ height. Compared to the three-dimensional Japanese CCRN/NIES chemistry-coupled AGCM (Takigawa et al., 2002), vertical profiles of $\mathrm{SO}_{2}$ are in good agreement in the tropics and $\mathrm{NH}$ 
a)
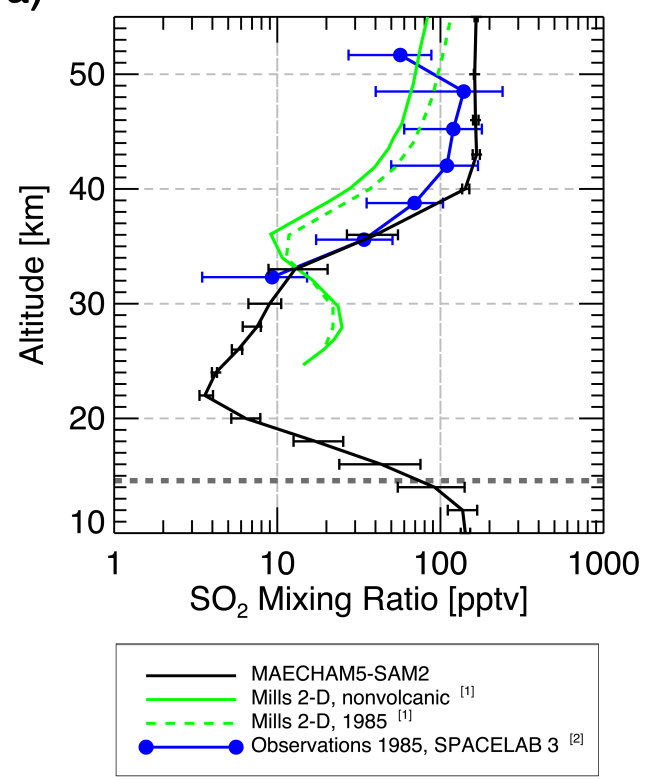

b)
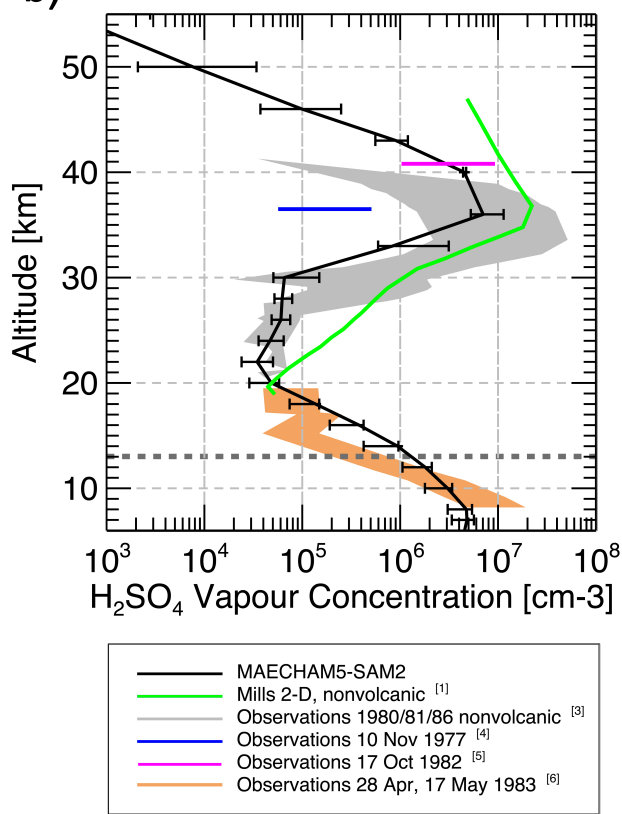

Fig. 3. Vertical profiles of modelled precursor gases in the Northern Hemisphere compared to results by ${ }^{1}$ Mills et al. (2005a) and observations from ${ }^{2}$ Rinsland et al. (1995), ${ }^{3}$ Arnold et al. (1981), Viggiano and Arnold (1981), Schlager and Arnold (1987), and Reiner and Arnold (1997), ${ }^{4}$ Arnold and Fabian (1980), ${ }^{5}$ Arnold and Qiu (1984), and ${ }^{6}$ Heitmann and Arnold (1983). ${ }^{5}$ and ${ }^{6}$ were conducted in the El Chichón period and ${ }^{4}$ in a near background stratosphere prior the El Chichón eruption. For MAECHAM5-SAM2 the median of the zonally averaged climatological monthly means of the stratospheric background period 1996-2006 are shown, respective minima and maxima are represented as deviation from the median. Mills et al. (2005a) data for nonvolcanic conditions refer to years prior El Chichón. (a) $\mathrm{SO}_{2}$ mixing ratio for April and May from 26 to $32^{\circ} \mathrm{N}$. (b) $\mathrm{H}_{2} \mathrm{SO}_{4}$ vapour concentration for June, September and October at $43^{\circ} \mathrm{N}$. In both figures the modelled tropopause height is marked by a dashed gray line.
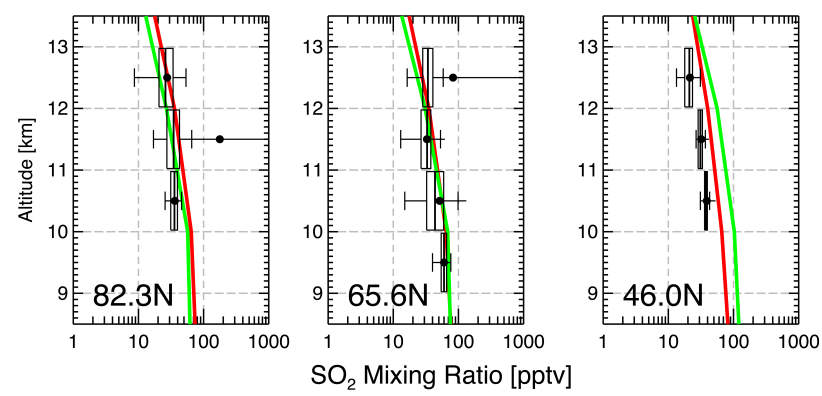

Fig. 4. Vertical profiles of modelled $\mathrm{SO}_{2}$ at mid and high latitudes of the Northern Hemisphere in comparison with observational data from the NASA SOLVE campaign, conducted between December 1999 and March 2000 (Lee et al., 2003). Observations, in black, were rebinned to $1 \mathrm{~km}$ intervals. Shown are medians and the interquartile range (IQR), expressed as 0.25 and 0.75 percentiles, of the samples. Circles mark arithmetic mean values. The spread of the data is shown as whiskers denoting $1.5 \times$ IRQ values, and outliers larger than that. Only measurements above the tropopause were considered. Model data are seasonal averages from 1999/2000 zonal means (DJF in red, MAM in green). mid-latitudes. In our simulation, larger $\mathrm{SO}_{2}$ mixing ratios are found in the tropical tropopause layer (TTL), and up to $80 \%$ lower $\mathrm{SO}_{2}$ mixing ratios are seen in our simulation above $20 \mathrm{~km}$ in regions where the stratospheric aerosol abundance is largest. The obvious difference to our and abovementioned model studies is that the stratospheric $\mathrm{SO}_{2}$ reservoir above $30 \mathrm{~km}$ is not reproduced in the CCRN/NIES model. They do not consider the $\mathrm{SO}_{2}$ forming bimolecular reaction between $\mathrm{SO}$ and the $\mathrm{NO}_{2}$ radical. This reaction is suspected to largely contribute to the formation of the stratospheric $\mathrm{SO}_{2}$ reservoir because in the stratosphere peak $\mathrm{NO}_{2}$ mixing ratios are found above regions of peak aerosol mixing ratios (e.g. Gordley, 1996), and, according to JPL/NASA (2003), the reaction is temperature insensitive and its rate is more than one order of magnitude larger than that of other sulphur converting bimolecular reactions. Noteworthy is also a very weak stratospheric $\mathrm{H}_{2} \mathrm{SO}_{4}$ vapour concentration in the CCRN/NIES model. This indicates that most of the vapour condenses onto aerosols since Takigawa et al. (2002) do not consider new particle formation from the gas phase. The one-dimensional stratospheric aerosol model of Turco et al. (1979) and Toon et al. (1979) predicted profiles for $\mathrm{SO}_{2}$ and sulphuric acid vapour very similar to those shown in Fig. 2. 
Differences are seen in the representation of upper stratospheric mixing ratios of $\mathrm{SO}_{2}$, which are up to one order of magnitude larger in our simulation, and of gaseous $\mathrm{H}_{2} \mathrm{SO}_{4}$, which do not show a distinct negative gradient above $26 \mathrm{~km}$.

A model-intercomparison in SPARC/ASAP (2006) revealed only minor differences between the models regarding the OCS abundance in the atmosphere. Models agree to a large extend with observations made in the stratosphere. Our offline data are based on these published data, and so it is assumed that OCS mixing ratios are well represented in our model.

Despite different representations of stratospheric dynamics in the above mentioned models, one-dimensional models behave like global models with respect to the representation of stratospheric precursor abundance. Significant differences in the simulation of some of the key characteristics seem to result from parametrised processes and missing links in sulphur chemistry schemes.

\subsection{Global aerosol distribution}

The annual mean burden of modelled sulphate aerosol is shown in Fig. 5. Tropospheric sulphate dominates, since, as analysed in Sect. 3.1, stratospheric aerosol contribute to less than $20 \%$ to the global annual mean sulphate mass of the atmosphere. The modelled sulphate burden is in agreement with sulphate components of other model studies which utilise comparable emission scenarios (e.g. Stier et al., 2005; Ma and von Salzen, 2006). Particulate sulphate is concentrated in regions of high anthropogenic sulphur emissions, i.e. industrialised regions in South East Asia, Europe, and North America. Significant dispersion of aerosols to North Africa and the Middle East occurs in the planetary boundary layer, which is is also seen in aerosol mixing ratios at the surface (Fig. 6a). Zonal homogenisation of the atmosphere's aerosol abundance increases with altitude (Fig. $6 \mathrm{~b}$ and c). In the stratosphere (Fig. 6c), the aerosol layer is well stratified and, due to low air density, the mixing ratio in the tropics is approximately as high as in the terrestrial boundary layer. In the free troposphere the mixing ratio of sulphate aerosol is approximately one order of magnitude lower.

The annual mean total particle number concentration $\left(N_{\mathrm{T}}\right)$ is dominated by ultra-fine particles throughout the atmosphere. As in other model studies, e.g. Ma and von Salzen (2006), at the surface the global distribution of the aerosol number concentration is very well correlated with the aerosol mixing ratio. Largest number concentrations are found over continental regions and are associated with anthropogenic pollution. Primary emissions occur mainly in the accumulation mode. Thus, they are less reflected in the total number concentration near the surface (with exceptions in continental regions near the equator) and in the total sulphate aerosol mixing ratio. The global dispersion of $N_{\mathrm{T}}$ in the boundary layer is less obvious than for the mixing ratios, indicating a rather fast ageing of aerosols, which is

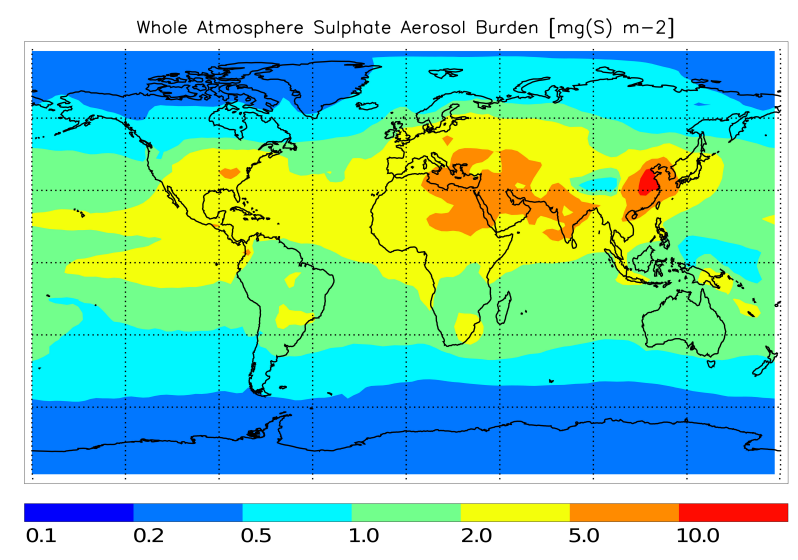

Fig. 5. Global distribution of the modelled annual mean of sulphate aerosol burden in the last year of integration.

associated with a reduction of ultra-fine particle number concentration. In East Antarctica and over Greenland, where the aerosol mixing ratio is lowest in the model, number densities of more than $5 \times 10^{3} \mathrm{~cm}^{-3}$ are found. Here aerosols are formed due to binary homogeneous nucleation in low temperature/high relative humidity environments (see Easter et al., 2004; Spracklen et al., 2005; Ma and von Salzen, 2006).

$N_{\mathrm{T}}$ increase with altitude, reaching maxima in the midlatitude free troposphere, where binary homogeneous nucleation rates are largest (Stier et al., 2005; Spracklen et al., 2005; Makkonen et al., 2009). Due to the importance of new particle formation for the total particle concentration in the atmosphere, above the boundary layer a pronounced anticorrelation between total number density and mixing ratio of sulphate is seen in Fig. 6. This becomes especially apparent in the stratosphere, where the rates of new particle formation are largest in the polar vortices (see Fig. $7 \mathrm{~b}$ and c) during spring.

Figure 7 shows zonal means of the seasonally averaged aerosol mass mixing ratio, nucleation rate, and nucleation mode number density for the $11 \mathrm{yr}$ analysis period. The tropical stratospheric reservoir (TSR; Trepte and Hitchman, 1992; Hitchman et al., 1994), a region which is quasi isolated from meridional transport, as well as the isolated air masses in the SH polar vortex are clearly seen in the modelled aerosol mixing ratio (Fig. 7a). The distinct staircase patterns found in the subtropical mixing ratio result from interactions between advective transport by the mean meridional circulation, the meridional circulation associated with the quasibiennial oscillation, the semi-annual oscillation, and effects of isentropic mixing by absorption of planetary wave energy (Baldwin et al., 2001). In agreement with findings of Hitchman et al. (1994) on the basis of aerosol data from the spaceborne SAM and SAGE instruments, a transport regime can be identified in the lower stratosphere, where particles are transported poleward and downward during winter. These 
a)

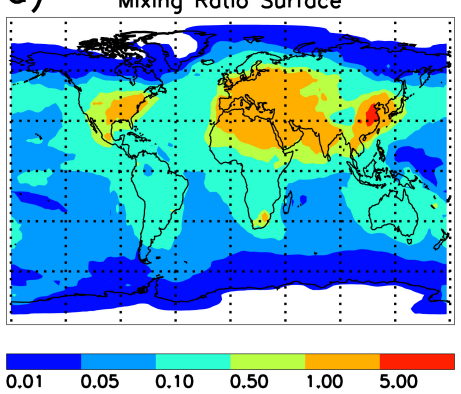

d)

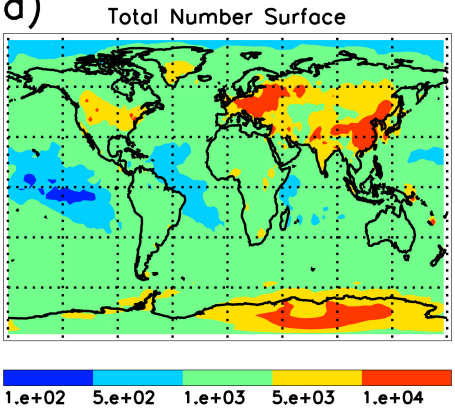

b)

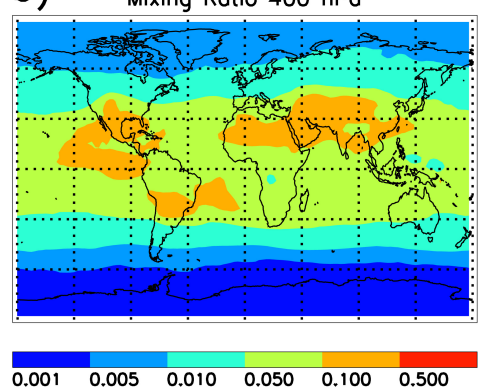

e)

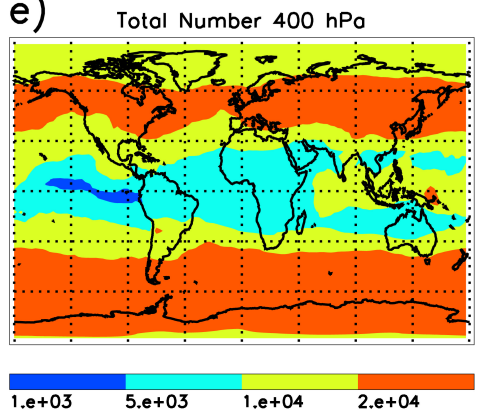

C) Mixing Ratio $30 \mathrm{hPo}$

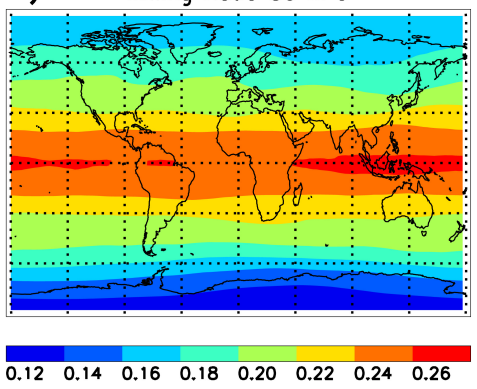

f)

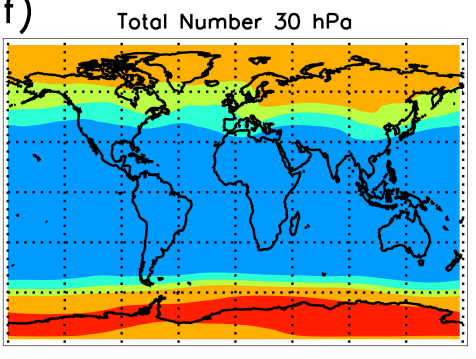

$\begin{array}{llllll}1 . e+01 & 2 . e+01 & 5 . e+01 & 7 . e+01 & 1 . e+02 & 2 . e+02\end{array}$

Fig. 6. Global distribution of modelled annual mean sulphate aerosol mixing ratios (top row) and total particle number concentrations (bottom row) in the last year of integration at the surface (a and d), in the free troposphere at $400 \mathrm{hPa}(\mathbf{b}$ and $\mathbf{e})$, and in the stratosphere at $30 \mathrm{hPa}$ (c and f). Mixing ratios are expressed as ppbm and concentrations in $\mathrm{cm}^{-3}$.

patterns persist into subsequent equinoctial seasons and are most pronounced in the NH. The same authors deduced an upper transport regime in the tropics during summer (above $22 \mathrm{~km}$ ), which is also reflected in our results in poleward oriented mixing ratio gradients in the upper branches of the TSR.

There is not much evidence from the modelled aerosol mixing ratio distribution that the high abundance of aerosols within the TSR originates exclusively from sulphate particles of tropospheric origin being transported into the LS by tropical upwelling. Instead, in boreal summer a significant flux of tropospheric particles reaches the LS in the subtropics and midlatitudes. The regions, where in our model aerosols are uplifted into the LS correspond to cells of tropospheric convection over the Asian Monsoon/Tibetan Plateau region, which is one of the main pathways for the crosstropopause transport of atmospheric moisture and other trace gases (see Fueglistaler et al., 2009, and references therein). Aerosols reaching the LS are transported poleward within the lower stratosphere, but a significant amount of particles also reaches the tropics by transport within the high altitude Monsoon anticyclone (Bannister et al., 2004; Fu et al., 2006).

Preferred regions where new sulphate droplets are formed in the model are the free troposphere above $500 \mathrm{hPa}$ as well as the winter and spring polar vortices above the $70 \mathrm{hPa}$ pressure altitude (Fig. 7b). Within a few kilometres above the tropopause, where temperatures are as low as $200 \mathrm{~K}$, the
Vehkamäki parametrisation of binary homogeneous nucleation predicts a minimum in the nucleation rate, which is not seen in other studies using the models ECHAM4-SAM (Timmreck, 2001) or AER (Weisenstein et al., 1997). A second maximum in tropical stratospheric nucleation rates is seen between 60 and $50 \mathrm{hPa}$, leading to remarkably high nucleation mode number densities of $<10 \mathrm{~cm}^{-3}$ throughout the tropical lower stratosphere, up to the $30 \mathrm{hPa}$ pressure altitude. Brock et al. (1995) showed particle mixing ratio profiles from measurements in the tropics in March 1994, when Mt. Pinatubo aerosols declined to near-background levels. The profiles exhibit that total number mixing ratios of volatile particles are largest in the free troposphere, but also reveal a minimum directly above the tropopause and a second maximum above, centred around $70 \mathrm{hPa}$. The nucleation rate estimates by Brock et al. (1995), however, have a lower vertical resolution than our simulation and, hence, can not show the minimum above the tropopause as seen in Fig. 7b. These observations and our results suggest, that it is likely that due to tropical upwelling ultra-fine particles of tropospheric origin contribute to the formation and maintenance of a stable stratospheric aerosol layer also in volcanically quiescent periods. Our calculations also reveal that a significant portion of TSR aerosol might be formed in the tropical LS, ages in higher altitudes and is then mixed into the extratropics.

High $\mathrm{CN}$ concentrations in the spring time polar vortices are observed in altitudes well above the aerosol layer 


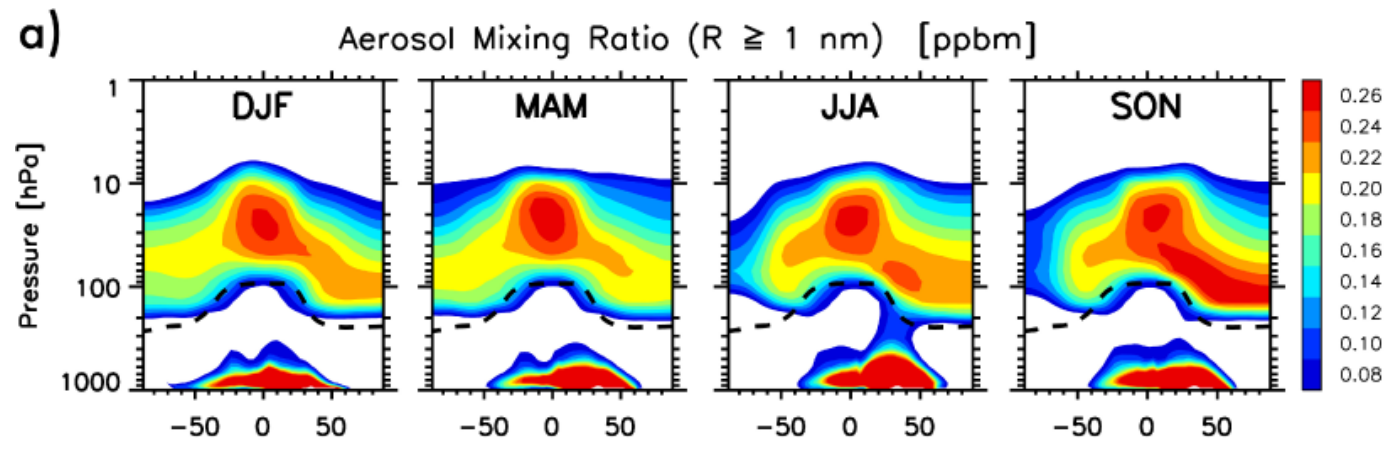

b)

Nucleation Rate [particle $\mathrm{cm}-3 \mathrm{~s}-1$ ]
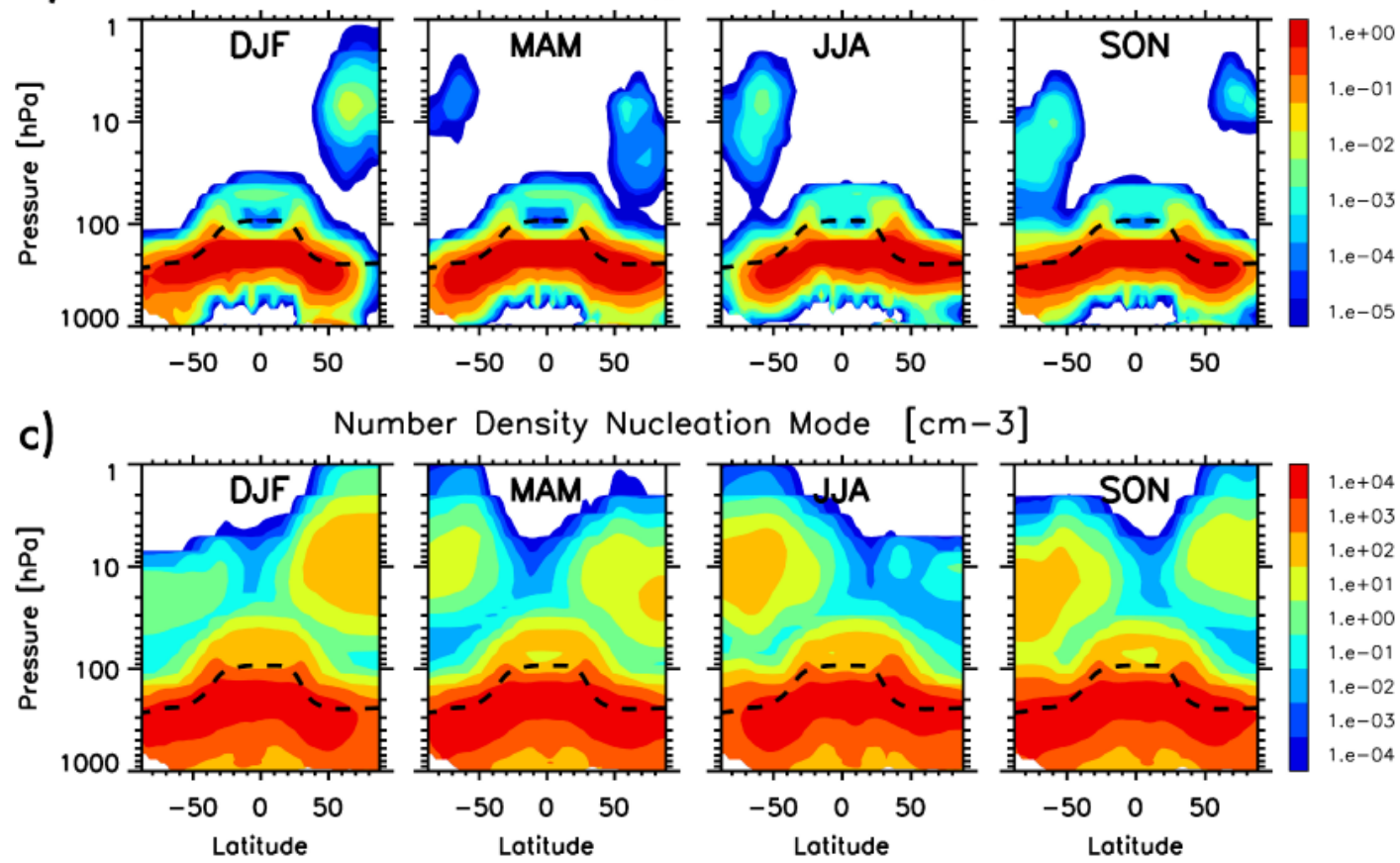

Fig. 7. Seasonal averaged climatological zonal mean (a) sulphate aerosol mass mixing ratio, (b) rate of new particle formation, and (c) nucleation mode number concentration.

(reviewed in SPARC/ASAP, 2006). Zhao and Turco (1995) first suggested, using a one-dimensional model, that the formation of an Antarctic stratospheric CN layer strongly depends on the subsidence of a non-condensable gas like $\mathrm{SO}_{2}$ in the polar night vortex. Mills et al. (1999) and Mills et al. (2005a) showed that in the upper stratosphere $\mathrm{SO}_{2}$ originates from photolysis of $\mathrm{H}_{2} \mathrm{SO}_{4}$ and is transported poleward with the mean meridional circulation. In the descending air masses of the Antarctic polar vortex $\mathrm{SO}_{2}$ is rapidly oxidised when sunlight returns in spring triggering the formation of the polar stratospheric $\mathrm{CN}$ layer. Furthermore they showed that, nearly independent on photochemistry mechanisms, which are thought to account for a stabilised stratospheric reservoir of $\mathrm{SO}_{2}$, new particle formation according to the classical nucleation theory is likely also in polar winters. However, in the southern polar vortex a sharp increase in the $\mathrm{CN}$ concentration is not predicted until enough gaseous $\mathrm{H}_{2} \mathrm{SO}_{4}$ is supplied for condensation in late August. This formation of polar stratospheric $\mathrm{CN}$ layers is reproduced in our model (Fig. 7b). In the Arctic polar vortex nucleation occurs at altitudes between 1 and $10 \mathrm{hPa}$ also in winter, with stronger rates at the end of the season. In March, nucleation rates are of similar strength (not clearly reflected in Fig. 7b due to seasonal averaging), but centred at lower altitudes around $20 \mathrm{hPa}$. In the Antarctic stratosphere significant nucleation rates are seen at $10 \mathrm{hPa}$ in April and July. When sunlight returns in late August, rates of new particle formation increase to $5 \times 10^{-3} \mathrm{~cm}^{-3} \mathrm{~s}^{-1}$ in descending air masses below $10 \mathrm{hPa}$ and persist until late October. Over both poles polar stratospheric $\mathrm{CN}$ layers are formed readily after nucleation events produce high concentrations of particle nuclei (10 to several 100 particles per $\mathrm{cm}^{-3}$ ) because coagulation efficiently removes ultra-fine particles, so that aerosols are rapidly growing to detectable sizes, see Sect. 3.5. Over Antarctica MAECHAM5-SAM2 predicts peak CN concentrations slightly higher than observed. However, location, 
subsidence as well as depletion of the $\mathrm{CN}$ layer correspond well with $\mathrm{CN}$ counter observations by e.g. Hofmann et al. (1989).

Meridional transport of stratospheric aerosols is not restricted to transport by the mean meridional circulation of the stratosphere. From Fig. 7c, an efficient lateral mixing of ultra-fine particles from the polar vortices into stratospheric mid and low latitudes due to Rossby wave activity (e.g. Waugh et al., 1994) can be deduced. There is evidence for a stronger wave activity in the $\mathrm{NH}$ since in the middle stratosphere gradients in number density appear stronger than in the SH. Although no nucleation occurs in these regions of the stratosphere, ultra-fine particles mixed to mid-latitudes grow to larger sizes or evaporate, dependent on the partial vapour pressure of $\mathrm{H}_{2} \mathrm{SO}_{4}$ (Fig. 8).

The upper branch of the stratospheric aerosol layer is not only a region where aerosols shrink in size due to the evaporation of sulphuric acid and water into the gas phase. Figure 8 shows model predicted climatologies of the zonal mean $\mathrm{H}_{2} \mathrm{SO}_{4}$ vapour pressure as well as the concentration of sulphuric acid vapour, which is transferred from the gas to the particle phase (condensation) and vice versa (evaporation). The ability of sulphuric acid vapour to condense onto preexisting particles is strongly reduced at the cold tropopause. In the lower stratosphere, from a few kilometres above the tropopause to regions where sulphate aerosol evaporates, the mass transfer onto the particles remains remarkably constant. This region corresponds to the central region of the aerosol layer. In this region, the missing meridional gradient in the mass transfer concentration of the $\mathrm{H}_{2} \mathrm{SO}_{4}$ condensation process implies that, at least in the stratospheric background, condensational growth is approximately constant over broad regions of the aerosol layer. Consequently, one may assume that the shape of particle size distributions in those region of the LS is similar from the tropics to the extratropics. Thus, we investigated aerosol size distributions in regions where the meridional gradient in the condensation transfer concentration is apparently weak, i.e. between $1 \times 10^{3} \mathrm{~cm}^{-3}$ and $5 \times 10^{3} \mathrm{~cm}^{-3}$. We found that for approximately constant nucleation rates the balance between particle growth due to $\mathrm{H}_{2} \mathrm{SO}_{4}$ condensation and growth due to coagulation does not differ significantly in this region (except in high latitudes near $30 \mathrm{hPa}$, where small particles evaporate quickly). For larger nucleation rates, coagulation becomes a more effective sink for aerosols with $R<0.07 \mu \mathrm{m}$.

In the climatologies of condensing and evaporating aerosols, in the Fig. $8 \mathrm{~b}$ and c, regions of vapour condensation above $20 \mathrm{hPa}$ overlap with regions where aerosols evaporate. This is a somewhat surprising result, because in the climatological mean the $\mathrm{H}_{2} \mathrm{SO}_{4}$ vapour pressure appears to be too large to allow $\mathrm{H}_{2} \mathrm{SO}_{4}$ molecules to condense onto particles. Condensation at this high altitudes becomes feasible when planetary waves break in the stratospheric Surf Zone (McIntyre and Palmer, 1984) and cause fluctuations in the stratospheric temperature, which in turn change the direction
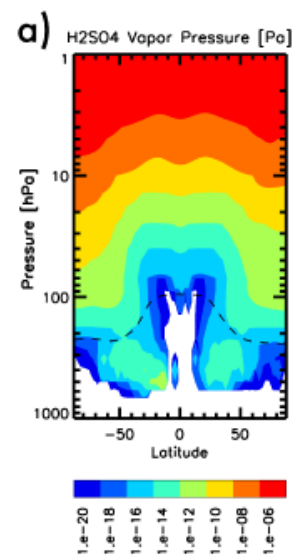

b)

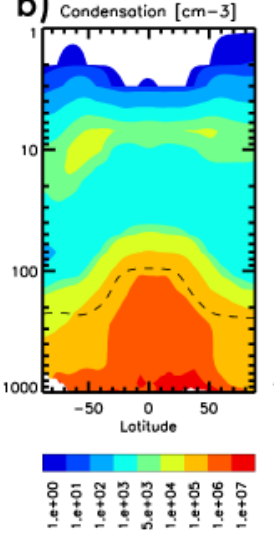

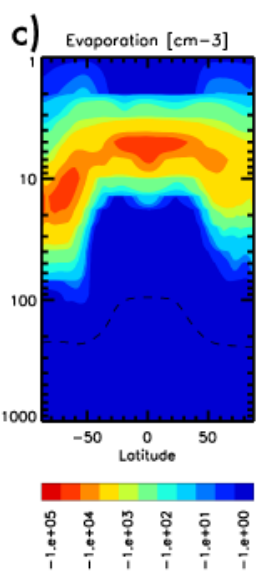

Fig. 8. Calculated climatological zonal mean (a) $\mathrm{H}_{2} \mathrm{SO}_{4}$ vapour pressure and the transfer concentrations of the processes (b) $\mathrm{H}_{2} \mathrm{SO}_{4}$ condensation and (c) $\mathrm{H}_{2} \mathrm{SO}_{4}$ evaporation. The evaporation transfer concentration is negative when mass transfer onto aerosols (b) is defined positive. Note an inverted colour shading in (c).

of the $\mathrm{H}_{2} \mathrm{SO}_{4}$ mass transfer. Such fluctuations last a couple of days, so that in the time average both processes seem to coexist. Hence, in these regions sporadically occurring $\mathrm{H}_{2} \mathrm{SO}_{4}$ condensation extends the life time of intrinsically evaporating aerosols.

Detailed investigations of the interannual variability of the modelled stratospheric aerosol layer, in particular regarding the quasi-biennial oscillation, are given in a companion paper (Hommel et al., 2011).

\subsection{Stratospheric aerosol climatology}

In this section, the model climatology of integrated aerosol quantities is compared with data retrieved from the spaceborne SAGE II instrument. The integral of the model results is taken for particles exceeding $50 \mathrm{~nm}$ in radius in order to achieve comparability with detection limitations of optical instruments (Dubovik et al., 2000; Pitari et al., 2002; Thomason et al., 2008; Kokkola et al., 2009).

Differences between the two SAGE II climatologies are small compared to the obvious differences between individual satellite and model climatologies (Fig. 9). In general, a high bias is found in the AMES retrieved SAD and VD relative to UOX retrieved values, whereas the two algorithms retrieve a quite similar aerosol effective radius. This high bias is pronounced in the mid-latitudes and subtropics. Above the main regions of the aerosol layer, were the aerosol mixing ratio tends to zero, the AMES algorithm retrieves too large $R_{\text {eff. }}$ From Fig. 9 it can be seen that relative to SAGE II higher moments of the aerosol distribution are better represented in the model simulation than lower moments. Below $20 \mathrm{~km}$, the deviation of model simulated SAD and VD from SAGE II exceeds the range of retrieval uncertainties (see Sect. 2.4). The variability of the satellite retrieved second 

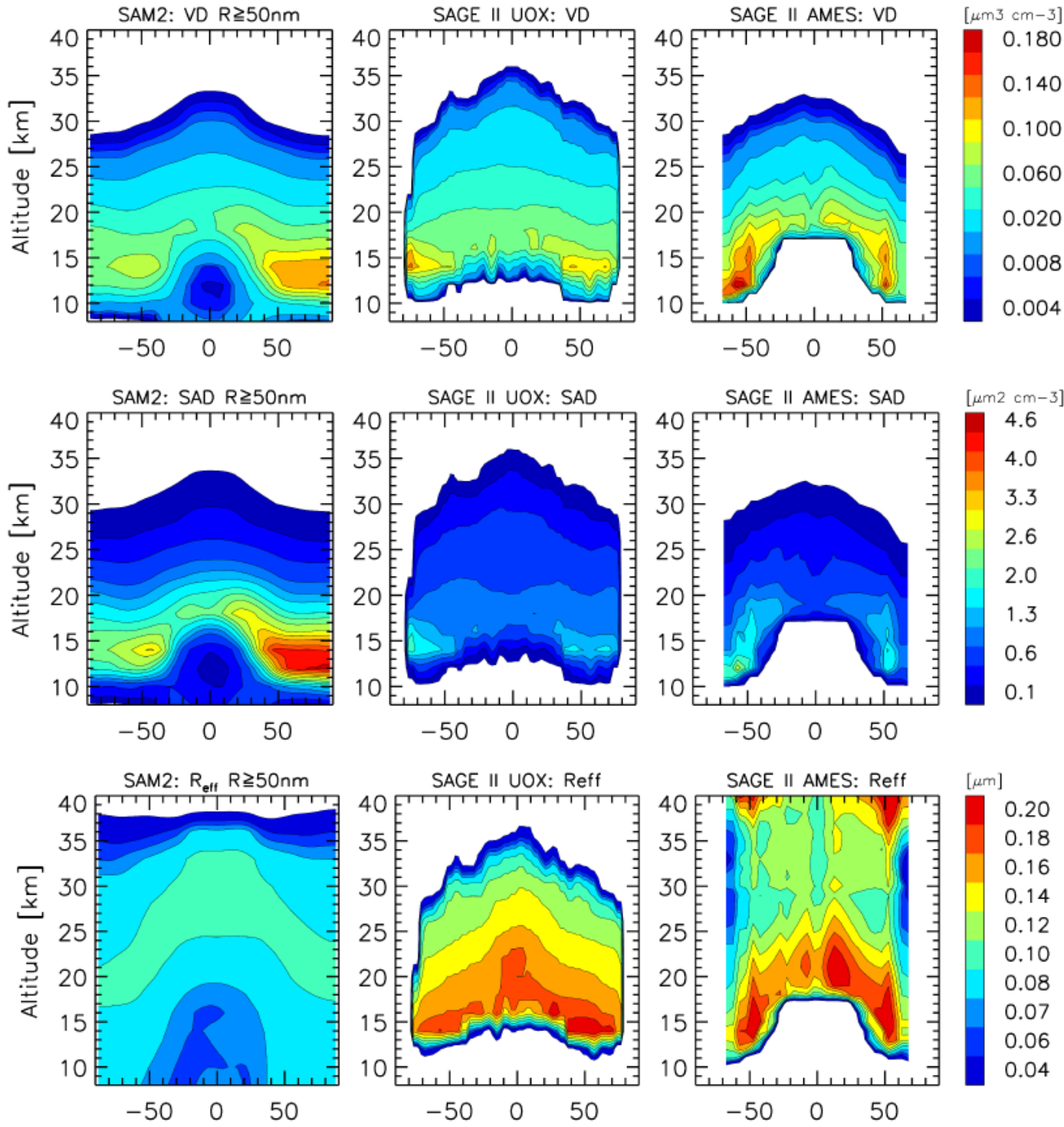

Fig. 9. Modelled climatologies (left column) of aerosol volume density (upper row), aerosol surface area density (middle row), and effective radius (bottom row), in comparison with SAGE II retrievals of the University of Oxford (Wurl et al., 2010, middle column) and NASA AMES laboratory (Bauman et al., 2003a,b, right column). All data for 1998 as zonal annual means.

and third moments of the aerosol distribution (SAD and VD) is much larger than in the model, mainly due to its relatively coarse spatial resolution. This also affects the model's ability to reproduce strong meridional gradients, which in particular are seen in extratropical SAD's of the AMES retrieval. In the model a distinct asymmetry in the meridional distribution of VD and SAD is found, whereas the effective radius does not differ much over the aerosol layer. Instead the SAGE II retrieved $R_{\text {eff }}$ is larger over the Northern Hemisphere and lower values are seen south of the equator in both retrievals within a few kilometres above the tropopause. Here the model underestimates $R_{\text {eff }}$ by more than $150 \%$. Also the satellite derived $R_{\text {eff }}$ exhibit a strong vertical gradient, with largest values found above the tropopause and low values in regions where sulphate droplets evaporate (above $27 \mathrm{~km}$ ).

The asymmetry in the modelled second and third moment is explained as follows: as shown before, the modelled stratospheric aerosol layer is strongly influenced by convective uplift over the Asian Monsoon regions, which transports significant amounts of particles, formed and grown to Aitken mode sizes in the free troposphere, into the LS. Those particles increase the surface area and, to a lesser extend, the volume density. Due to the large numbers of those particles entering the LS, they also contribute to the total aerosol mass (Fig. 7a) by further absorbing $\mathrm{H}_{2} \mathrm{SO}_{4}$ and growing to larger sizes. In the annual mean effective radius, however, this contribution 

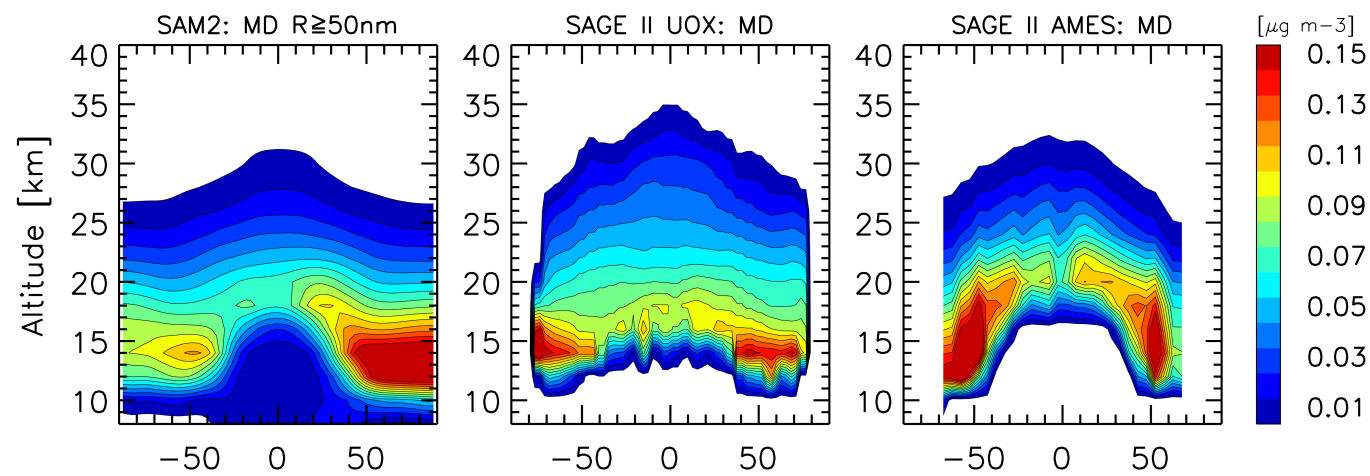

Fig. 10. As in Fig. 9, except for aerosol mass densities.

is not reflected. This fact and the homogeneity of the modelled $R_{\text {eff }}$ have two reasons: first, due to the one-moment approach of the aerosol scheme (aerosol number is not prognostic, hence not conserved, Adams and Seinfeld, 2002), and, second, due to the operator splitting technique used to solve competing processes within relatively large global model time steps, the aerosol volume to surface relationship, which determines $R_{\text {eff }}$ (e.g. Grainger et al., 1995), is relatively tied and not a function of altitude. Hence, the modelled effective radius is a constant when an aerosol population in a certain region of the stratosphere is not affected by external sources or sinks, i.e. new particle formation or vertical updraft of sub-population particles. We found a reduction of a few percent in the modelled $R_{\text {eff }}$ during the summer months in the extratropical updraft regions of the LS. Their contribution to the zonal annual mean, however, is too weak to be noticeable.

In Fig. 10 the climatological zonal mean aerosol mass density (MD) as predicted by the model is compared with respective MD's derived from the two different SAGE II climatologies. MD's of the latter were derived from volume densities as shown in Fig. 9, assuming that stratospheric sulphate aerosols are homogeneously composed throughout the stratosphere with a sulphuric acid weight percentage of $75 \%$ and a solution density of $1.7 \mathrm{~g} \mathrm{~cm}^{-3}$. The model MD was diagnosed online, depending on the appropriate particle composition as predicted by the model's thermodynamical parametrisations.

The characteristic distribution of the aerosol MD in the LS is similar to that of the VD (Fig. 9 upper row) although meridional and vertical gradients appear to be stronger in the MD. The quantitative agreement between model and SAGE II is satisfying for this parameter, in particular in the $\mathrm{NH}$. In the SH, poleward from midlatitudes and below $18 \mathrm{~km}$, a general underestimation in the order of $\sim 30 \%$ of modelled MD's is seen.

Mass densities shown for the two-dimensional model AER in Weisenstein et al. (1997) are in qualitative and quantitative agreement with our study. MD's of this model shown in SPARC/ASAP (2006) are 35\% larger in the extratropical lower stratosphere, also showing enlarged aerosol masses in the TTL. The latter feature is neither found in our simulation nor in SAGE II retrieved aerosol mass densities. Table 3 summarises values of this quantity from literature for northern hemispheric extratropics, including earlier SAGE II interpretations as well as estimates from in situ observations. Also here the overall agreement between models of different complexity and between models and observations is obvious. Aerosol mass is a very robust parameter, with small deviations between the models. Also the resolution of the discretised aerosol size spectrum seems to have a minor effect on the predicted MD. This can be derived also from Yue et al. (1994) for the pre-Pinatubo period, which as Kent et al. (1995) utilises an early version of the SAGE II retrieval algorithm. Results of Kent et al. (1995), however, are up to twice as large as other SAGE II and model data shown in Table 3. In situ measurements below $21 \mathrm{~km}$ are distinctly smaller. Kent et al. (1995) derived MD's by multiplying measured extinctions with a factor representing the particle volume-to-extinction ratio and assumed that stratospheric aerosols are lognormally distributed and their standard deviation is constant. Yue et al. (1994) followed an approach very similar to our online diagnostics of MD: the extinction derived volume density was multiplied with thermodynamically calculated aerosol densities and normalised sulphuric acid mass fractions. To analyse whether the Kent et al. (1995) assumption yields positive biased MD's is beyond the scope of this paper, but it is likely that their approach is very sensitive in a background stratosphere.

\subsection{Comparison with in situ measurements}

In this section we evaluate the vertical distribution of the modelled stratospheric aerosol abundance by comparing the model predicted aerosol size with in situ measurements from the ballon-borne optical particle counter (OPC) operated by the University of Wyoming (e.g. Deshler et al., 2003a). All model data shown in this section are characteristic for the 
Table 3. Stratospheric aerosol mass densities in $\left(\mu \mathrm{g} \mathrm{m}^{-3}\right)$ at $40^{\circ} \mathrm{N}$ and three altitudes, derived from different models and oberservations.

\begin{tabular}{|c|c|c|c|c|c|c|c|c|c|c|}
\hline & \multicolumn{5}{|c|}{ Models } & \multicolumn{4}{|c|}{ SAGE II } & \multirow{2}{*}{$\frac{\text { OPC/PCAS }}{\text { Kent et al. }^{9}}$} \\
\hline & SAM $2^{1}$ & $\mathrm{SAM}^{2}$ & AER $40^{3}$ & AER $40^{4}$ & AER $150^{5}$ & $\mathrm{UOX}^{6}$ & $\mathrm{AMES}^{7}$ & Yue et al. ${ }^{8}$ & Kent et al. ${ }^{9}$ & \\
\hline & Mean 1998 & Annual mean & Mean April & Annual mean & Annual mean & Mean 1998 & Mean 1998 & Mean Apr 1991 & \multicolumn{2}{|c|}{ Mean Pre-Pinatubo 1988-Apr 1991} \\
\hline $24 \mathrm{~km}$ & 0.03 & 0.05 & 0.05 & 0.04 & 0.04 & 0.04 & 0.03 & $\sim 0.05$ & $0.05-0.1$ & - \\
\hline $21 \mathrm{~km}$ & 0.08 & 0.08 & 0.07 & 0.08 & 0.07 & 0.07 & 0.08 & $\sim 0.08$ & $0.19-0.25$ & 0.1 \\
\hline $16 \mathrm{~km}$ & 0.12 & 0.10 & 0.13 & 0.17 & 0.13 & 0.11 & 0.12 & $\sim 0.13$ & $0.19-0.25$ & $0.03-0.06$ \\
\hline
\end{tabular}

Models: ${ }^{1}$ This work, 3-D, MAECHAM5, 35 bins; ${ }^{2}$ Timmreck (2001), 3-D, ECHAM4, 35 bins; ${ }^{3}$ Weisenstein et al. (1997), 2-D, 40 bins; ${ }^{4}$ SPARC/ASAP (2006), 2-D, 40 bins, and ${ }^{5}$ Weisenstein et al. (2007), 2-D, 150 bins. SAGE II : ${ }^{6}$ Wurl et al. (2010); ${ }^{7}$ Bauman et al. (2003a,b); ${ }^{8}$ Yue et al. (1994); and ${ }^{9}$ Kent et al. (1995). Data for OPC and PCAS (Passive Cavity Aerosol Spectrometer) are also taken from Kent et al. (1995).
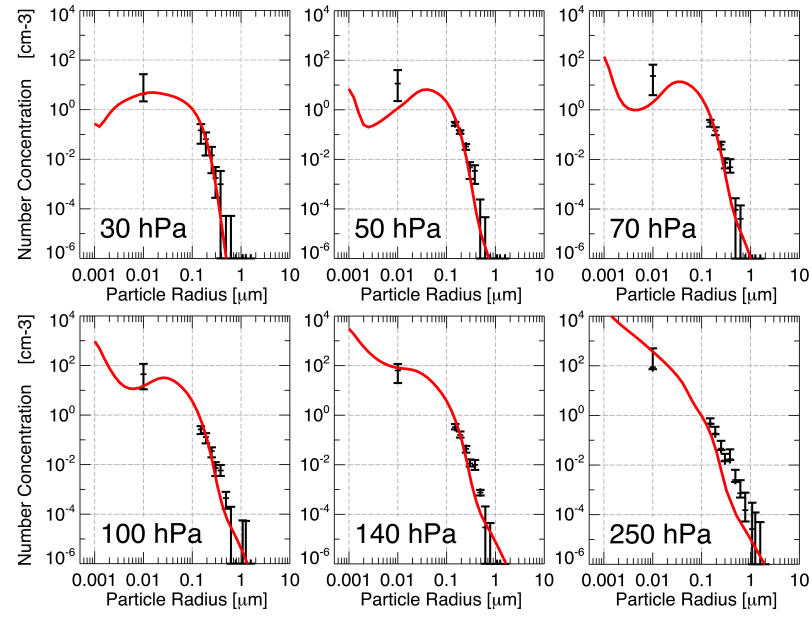

Fig. 11. Comparison of modelled size distributions with OPC measurements of particle number concentrations taken in the free troposphere and stratosphere over Laramie, WY for 2006 (Deshler et al., 2003a). Model data are represented by annual zonal means. For the OPC the median of all soundings in 2006, rebinned to the vertical resolution of the model, is shown. Whiskers denote the spread of the observations.

location where the instrument was launched (Laramie, WY, $41.3^{\circ} \mathrm{N}, 105.7^{\circ} \mathrm{W}$ ). During the time period of interest for this study, the balloon flights were conducted not very frequently. Table 4 provides an overview of available OPC soundings. All respective data records are considered in the following analysis. It has to be mentioned, that due to the scarceness of the OPC data we are not aiming to evaluate their time evolution with respect to a potential increase in the observed stratospheric aerosol abundance, as e.g. recently inferred from continuously operating Lidars at Mouna Loa $\left(\right.$ Hawaii, $19^{\circ} \mathrm{N}$ ) and Boulder (Colorado, 40 $\mathrm{N}$ ) (Hofmann et al., 2009).

Figure 11 compares model predicted annual zonal mean size distributions with OPC measured number concentrations of the individual OPC channels for 2006. For the calculation of the median from observed number concentrations we sampled the measurement data according to the layer heights as used in model postprocessing. Vertical whiskers denote the spread of the measurements from all soundings in the respective period. Figure 11 exposes significant differences in the representation of Aitken mode particles at 70 and $50 \mathrm{hPa}$ whereas the concentration of accumulation and coarse mode particles agree quite well with the observations. In this region of the aerosol layer, where aerosol mixing ratios are largest, the measured concentration of $\mathrm{CN}$ is approximately one order of magnitude larger than in the simulations. Above the peak aerosol mixing ratios, at $30 \mathrm{hPa}$, model and observations are in good agreement over the whole size range. Here temperatures clearly exceed $210 \mathrm{~K}$ and nucleation rates are significantly smaller than below this altitude, although sufficient concentrations of sulphuric acid vapour would be available to form new particles (see Fig. 3). Towards the tropopause, the model slightly underestimates the number of accumulation mode particles while overestimating the number density of very large coarse mode particles. Below the tropopause, at $250 \mathrm{hPa}$, this negative bias becomes even more distinct. Consistent with findings of Makkonen et al. (2009), in the UT the Vehkamäki parametrisation of binary homogeneous nucleation predicts very high numbers of nucleation mode particles, leading to an overestimation in the modelled $\mathrm{CN}$ concentration in the free troposphere.

In the main regions of the aerosol layer, bimodal aerosol size distributions are simulated. Towards the tropopause and below the shape of the size distributions transforms into monotonically decreasing curves since gas-to-particle partitioning overwhelms particle growth by coagulation.

An example of the seasonality in the size distributions is shown in Fig. 12 for the $50 \mathrm{hPa}$ layer. Here the model data are climatological means of the grid cells above the geographical position of Laramie. Measurements are shown as medians of all soundings conducted from 1998 to 2006, re-binned according to the vertical resolution of the model. Again, the spread of the measured number densities is shown as whiskers. Moderate annual cycles in the number concentrations can be seen for particles with $R \leq 20 \mathrm{~nm}$. In the model the annual cycle of ultra-fine particles with enhanced concentrations of freshly formed particles during summer is clearly demonstrated. The growth of nuclei to detectable sizes is affected by coagulation rather than by condensation. Particle 
Table 4. Overview of the University of Wyoming ballon-borne optical particle counter (OPC) measurements, at Laramie (WY, $41.3^{\circ} \mathrm{N}$, $105.7^{\circ} \mathrm{W}$; Deshler et al., 2003a) between 1998 and 2006.

\begin{tabular}{llllllllll}
\hline Season & \multicolumn{7}{c}{ Year } \\
\cline { 2 - 10 } & 1998 & 1999 & 2000 & 2001 & 2002 & 2003 & 2004 & 2005 & 2006 \\
\hline DJF & - & $10 \mathrm{Dec}$ & - & $10 \mathrm{Feb}$ & - & - & - & - & $09 \mathrm{Dec}$ \\
& & & & & & & & & $13 \mathrm{Feb}$ \\
$\mathrm{MAM}$ & $23 \mathrm{Apr}$ & $18 \mathrm{Mar}$ & $12 \mathrm{Apr}$ & - & $23 \mathrm{May}$ & - & - & $20 \mathrm{May}$ & $06 \mathrm{May}$ \\
& $29 \mathrm{May}$ & $20 \mathrm{Apr}$ & $24 \mathrm{May}$ & & & & & & \\
JJA & $05 \mathrm{Aug}$ & $23 \mathrm{Jun}$ & $13 \mathrm{Jul}$ & $25 \mathrm{Jul}$ & - & $28 \mathrm{Jul}$ & - & $07 \mathrm{Jul}$ & - \\
& & $21 \mathrm{Jul}$ & $31 \mathrm{Aug}$ & & - & & & \multirow{2}{*}{$17 \mathrm{Oct}$} & - \\
SON & - & $16 \mathrm{Sep}$ & - & - & - & - & - & - \\
\hline
\end{tabular}
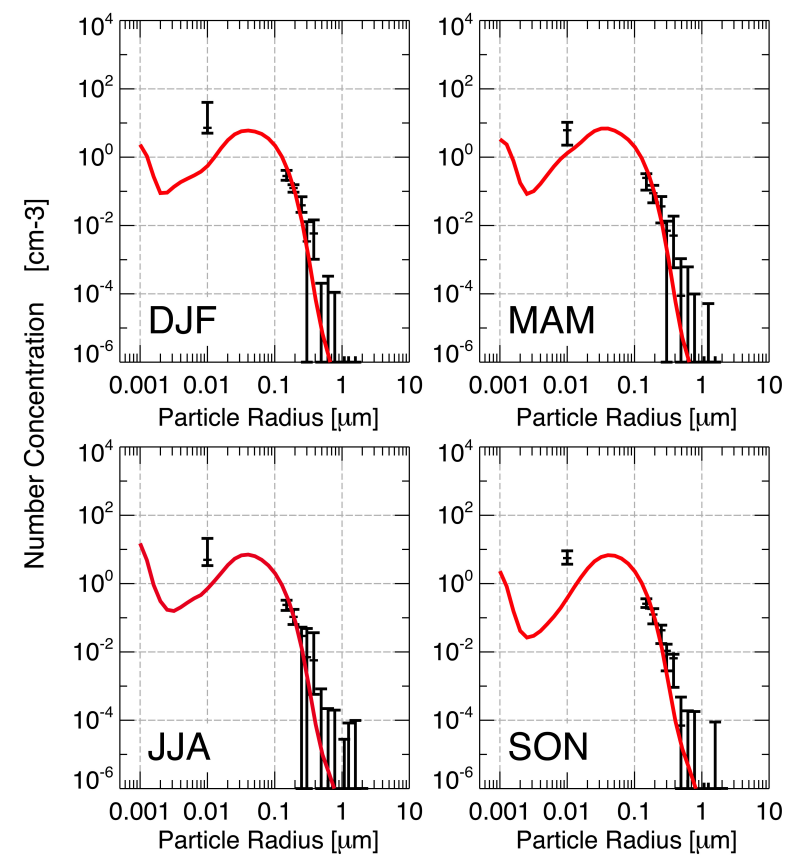

Fig. 12. Seasonal averaged aerosol size distributions in the centre of the stratospheric aerosol layer at $50 \mathrm{hPa}$ over Laramie, WY. The OPC data (black) as in Fig. 11, except for the years 1998 to 2006. Model data (red) are climatological means of the grid cells corresponding to the geographical position of the station.

growth by coagulation is characterised by an effective reduction of the number of ultra fine particles, which is accompanied by a moderately decreasing standard deviation of an unimodal size distribution. Condensational growth, however, does not reduce the number of growing particles. It instead leads to an effective reduction of the spread of a size distribution (Jacobson, 1997). Hence, the distinct minimum in the nucleation mode is caused by an overestimated coagulation efficiency of small mode particles. In the observations an annual cycle is seen in the variability of the measured number concentrations, in particular for $\mathrm{CN}$ and particles with $0.2 \leq R \leq 0.8 \mu \mathrm{m}$. The median of the data, however, does not vary significantly. The underprediction of $\mathrm{CN}$ concentrations is also known from other bin-resolved aerosol models, e.g. GLOMAP (D. Spracklen, personal communication, 2009). The source of the problem is not yet clear. Further investigations of the growth of ultra-fine particles under well defined conditions are necessary.

Figure 13 shows vertical profiles of the effective radius in the stratosphere over Laramie. Data representing observations were retrieved from surface area and volume densities, which in turn were derived from size distribution fitted to the measurements (ftp://cat.uwyo.edu/pub/permanent/ balloon/Aerosol_InSitu_Meas/US_Laramie_41N_105W).

Taking into account the uncertainties of the surface area and volume estimates from the measurements (Deshler et al., 2003a), the model reproduces reasonably well the effective radius in the stratosphere. In the model as well as in the observations the maximum effective radius is found where aerosol mixing ratios are largest $(16$ and $27 \mathrm{~km})$. In the model this feature is reproduced only when the parameter is retrieved for the whole aerosol spectrum. However then $R_{\text {eff }}$ is underestimated by at least $30 \%$. A better representation is achieved, in particular a few kilometres above the tropopause and above $25 \mathrm{~km}$, when the model spectrum is integrated only for the visible range of optical instruments.

From the size distributions shown in the Figs. 11 and 12 and the relationships between the different diagnosed aerosol parameters in the preceding sections, it is obvious that typical stratospheric background aerosol size distributions are bimodal rather than unimodal, as often suggested in literature (e.g. Pinnick et al., 1976; SPARC/ASAP, 2006). The first, very narrow mode is centred in the size regime of new particles, i.e. $R<0.01 \mu \mathrm{m}$. The median radius of the second, much broader mode, is located in the accumulation mode regime between $0.01 \mu \mathrm{m}$ and $0.1 \mu \mathrm{m}$. Fine mode particles important for heterogeneous processes in the stratosphere do 


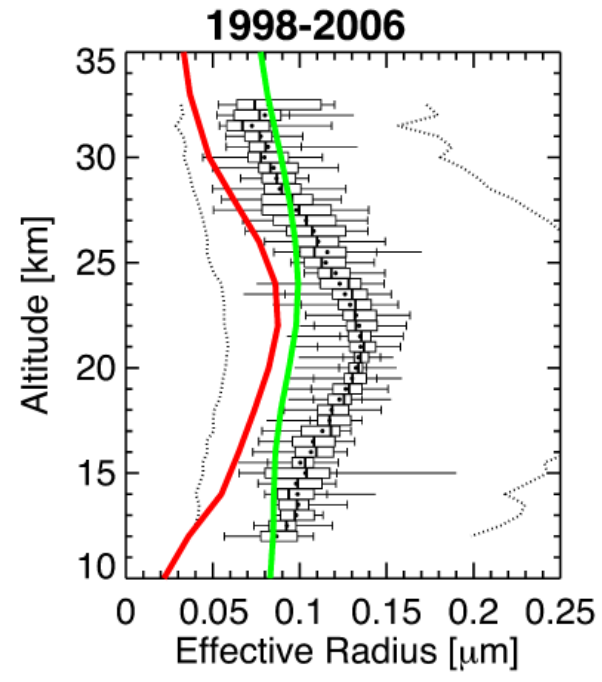

Fig. 13. Vertical profiles of the effective radius derived from OPC measurements in the stratosphere over Laramie (WY; Deshler et al., 2003a) compared to model results. The OPC data, in black, were rebinned according the vertical resolution of the model. Shown is the vertical profile of the data median. The box represents the interquartile range, i.e. 0.25 and 0.75 percentiels. Circles mark mean values of the measurements. The spread of the data is shown as whiskers denoting $1.5 \times$ IRQ values, and outliers larger than that. Dashed lines represent $R_{\text {eff }}$ when the error estimates of the underlying surface area and volume density integrals from size distributions fitted to measurements are taken into account, details are given in Deshler et al. (2003a). The model effective radius was retrieved for the whole spectrum ( $R \geq 1 \mathrm{~nm}$; red) and for the visible range of optical instruments ( $R \geq 50 \mathrm{~nm}$; green).

not only substantially contribute to integrated aerosol quantities. They also affect the size of the area weighted effective radius, a measure widely used to interpret radiative properties of aerosols, because condensational growth of ultra-fine particles enlarges the number concentration in the Aitken mode and lower accumulation mode. Hence, they enlarge the aerosol surface area and, to a lesser extent, the volume density. The more particles are formed the smaller is the calculated effective radius. In addition to the insensitivity of SAGE II retrieved integrated aerosol size parameters to fine mode particles yielding negatively biased surface areas (Thomason et al., 2008), this relation also accounts for the discrepancy of integrated aerosol size quantities from model and SAGE II (Fig. 9), which is largest for the effective radius. This relation also accounts for the underprediction of $R_{\text {eff }}$ relative to the Laramie OPC measurements, since the latter were inferred from bimodal size distribution fits to the measured number concentrations for $R>0.01 \mu \mathrm{m}$.

\section{Conclusions}

The size resolved aerosol module SAM2, incorporated into the middle-atmosphere climate model MAECHAM5, has been applied to investigate the stratospheric aerosol layer during an eleven year volcanically quiescent period. The model is evaluated against in situ observations and SAGE II retrieved integrated aerosol size quantities for the period when Mt. Pinatubo aerosols reduced to background levels after 1995 .

In situ measured size distributions of stratospheric aerosols in the NH mid-latitudes are fairly well reproduced by the model. In regions of the aerosol layer, where aerosol mixing ratios are largest, model predicted $\mathrm{CN}$ concentrations are underpredicted, indicating an overestimated coagulation efficiency in the model. Because nucleation from the gas phase is a major source of new particles in the stratosphere during volcanically quiescent periods, model predicted size distributions of stratospheric aerosols show a distinct bimodal structure over large areas of the LS.

The agreement between model and SAGE II retrieved integrated aerosol quantities related to the size of particles improves for higher moments of the aerosol size distribution. Lower moments as the effective radius are significantly smaller in the model in large areas of the stratosphere. This is due to limitations of remote sensing instruments at the bottom end of the aerosol spectrum and a priori constraints in the retrieval methods which do not take into account the formation and growth of new particles. This confirms "key finding two" of the SPARC Assessment of Stratospheric Aerosol Properties (2006), stating that the obvious consistency between in-situ and satellite measurements in a volcanically perturbed stratosphere is not maintained in periods of very low aerosol load, when aerosol key quantities significantly differ between the systems.

Major characteristics of the dynamics of stratospheric aerosols are reproduced. Transport regimes of tropical stratospheric aerosol have been identified from modelled mixing ratio gradients and correspond to observational findings based on satellite extinction measurements. A major pathway where aerosols in the model reach the stratosphere, is convective transport in the Asian Monsoon region during boreal summer. While this mechanism is vital for maintaining stratospheric trace gas abundances including water vapour, from global monitoring of UT/LS aerosol quantities this extra-tropical cross-tropopause transport was not evident so far. New particles are formed mainly in the free troposphere. However, nucleation is not unlikely above the cold point tropopause. But there at least one order of magnitude fewer particles than in the UT are formed. In polar spring, new particles are formed within the polar vortex in altitudes far above the tropopause, leading to well reproduced layers of sub-micron particles (CN layer) in the model. Consistent with observations, in subsequent equinoctial seasons these $\mathrm{CN}$ layers settle to lower altitudes and, when 
the aerosols are grown to larger sizes, are removed quickly from the stratosphere in diabatically descending air within the polar vortices or they even re-evaporate. The incorporation of aerosols into and their removal via PSC's are not considered in the model. We also simulated significant concentrations of fine mode particles in the stratospheric Surf Zone, where new particle formation is very unlikely. These aerosols are transported from polar regions into mid- and low latitudes through meridional mixing induced by planetary waves breaking at the edges of the polar vortices. This process is strongest in the winter hemisphere. In the evaporation regime of the stratospheric aerosol layer we found regions where the time mean sulphuric acid droplet evaporation coincides with $\mathrm{H}_{2} \mathrm{SO}_{4}$ vapour condensation due to small scale fluctuations in the stratospheric dynamics. This extends the aerosol lifetime in the Surf Zone so that particles are transported further poleward with the mean meridional circulation.

Although we only have a poor data base of observed sulphate precursor gas abundances in the UT/LS, the modelled concentrations of $\mathrm{SO}_{2}$ and sulphuric acid vapour are in good agreement to these few measurements and are less biased than those of other models. UT/LS measurements of $\mathrm{SO}_{2}$ mixing ratios made in the $\mathrm{NH}$ mid and high latitudes on a NASA DC8 research aircraft during SOLVE in Winter 1999/2000 show evidence that, at least in some regions, the $\mathrm{SO}_{2}$ abundance in the $\mathrm{LS}$ is captured well by the model.

From the results presented here we conclude that MAECHAM5-SAM2 is a suitable model for studies of the dynamics of stratospheric background aerosol. Its capability of treating also other aerosol compounds than sulphate as well as its performance in scenarios of enhanced stratospheric sulphur loading of whatever reason remains subject of future model development and investigation.

Acknowledgements. This work was supported by the EC projects PARTS and SCOUT-O3. We thank Peter Braesicke, Christoph Brühl, Terry Deshler, Marco Giorgetta, Hartmut Grassl, Don Grainger, Stefan Kinne, Silvia Kloster, Harri Kokkola, Shanhu Lee, Ulrike Niemeier, Declan O'Donnel, Benedikt Steil, Philip Stier, Manu Thomas, Larry Thomason, Hanna Vehkamäki, Albert Viggiano and many others for helpful discussions as well as Bärbel Langmann and Angelika Heil for critically reviewing the manuscript. We also thank two anonymous reviewers for their constructive critic that helped improving the original manuscript.

The service charges for this open access publication have been covered by the Max Planck Society.

Edited by: A. Sandu

\section{References}

Adams, P. J. and Seinfeld, J. H.: Predicting global aerosol size distributions in general circulation models, J. Geophys. Res., 107, 4370, doi:10.1029/2001JD001010, 2002.

Andres, R. J. and Kasgnoc, A. D.: A time-averaged inventory of subaerial volcanic sulfur emissions, J. Geophys. Res., 103, 25251-25261, 1998.

Angell, J. K., Korshover, J., and Planet, W. G.: Ground-based and satellite evidence for a pronounced total-ozone minimum in early 1983 and responsible atmospheric layers, Mon. Weather Rev., 113, 641-646, 1985.

Arnold, F. and Fabian, R.: First measurements of gas phase sulphuric acid in the stratosphere, Nature, 283, 55-57, 1980.

Arnold, F. and Qiu, S.: Upper stratosphere negative ion composition measurements and inferred trace gas abundances, Planet. Space Sci., 32, 169-177, 1984.

Arnold, F., Fabian, R., and Joos, W.: Measurements of the height variation of sulfuric acid vapor concentrations in the stratosphere, Geophys. Res. Lett., 8, 293-296, 1981.

Baldwin, M. P., Gray, L. J., Dunkerton, T. J., Hamilton, K., Haynes, P. H., Randel, W. J., Holton, J. R., Alexander, M. J., Hirota, I., Horinouchi, T., Jones, D. B. A., Kinnersley, J. S., Marquardt, C., Sato, K., and Takahashi, M.: The quasi-biennial oscillation, Rev. Geophys., 39, 179-229, 2001.

Bannister, R. N., O'Neil, A., Gregory, A. R., and Nissen, K. M.: The role of the south-east Asian monsoon and other seasonal features in creating the "tape-recorder" signal in the Unified Model, Q. J. R. Meteorol. Soc., 130, 1531-1554, 2004.

Barth, M. C., Rasch, P. J., Kiehl, J. T., Benkovitz, C. M., and Schwartz, S. E.: Sulfur chemistry in the National Center for Atmospheric Research Community Climate Model: Description, evaluation, features, and sensitivity to aqueous chemistry, J. Geophys. Res., 105, 1387-1415, 2000.

Bauman, J. J., Russell, P. B., Geller, M. A., and Hamill, P.: A stratospheric aerosol climatology from SAGE II and CLAES measurements: 1. Methodology, J. Geophys. Res., 108, 4382, doi:10.1029/2002JD002992, 2003a.

Bauman, J. J., Russell, P. B., Geller, M. A., and Hamill, P.: A stratospheric aerosol climatology from SAGE II and CLAES measurements: 2. Results and comparisons, 1984-1999, J. Geophys. Res., 108, 4382, doi:10.1029/2002JD002993, 2003b.

Baumgardner, D., Kok, G., and Raga, G.: Warming of the Arctic lower stratosphere by light absorbing particles, Geophys. Res. Lett., 31, 4383, doi:10.1029/2003GL018883, 2004.

Bekki, S. and Pyle, J.: Two-dimensional assessment of the impact of aircraft sulphur emissions on the stratospheric sulfate aerosol layer, J. Geophys. Res., 97, 15839-15847, 1992.

Borrmann, S., Solomon, S., Dye, J. E., Baumgardner, D., Kelly, K. K., and Chan, K. R.: Heterogeneous reactions on stratospheric background aerosols, volcanic sulfuric acid droplets, and type I polar stratospheric clouds: Effects of temperature fluctuations and differences in particle phase, J. Geophys. Res, 102, 36393648, 1997.

Brock, C. A., Hamill, P., Wilson, J. C., Jonsson, H. H., and Chan, K. R.: Particle formation in the upper tropical troposphere: A source of nuclei for the stratospheric aerosol, Science, 270, 1650-1653, 1995.

Burkholder, J. B. and McKeen, S.: UV absorption cross sections for $\mathrm{SO}_{3}$, Geophys. Res. Lett., 24, 3201-3204, 1997. 
Chin, M., Jacob, D., Gardner, G., Foreman-Fowler, M., Spiro, P., and Savoie, D.: A global three-dimensional model of tropospheric sulfate, J. Geophys. Res., 101, 18667-18690, 1996.

Chlond, A.: Locally modified version of Bott's advection scheme, Mon. Weather Rev., 122, 111-125, 1994.

Crutzen, P. J.: Albedo enhancement by stratospheric sulfur injections: A contribution to resolve a policy dilemma?, Climatic Change, 77, 211-219, 2006.

Cunningham, E.: On the Velocity of Steady Fall of Spherical Particles through Fluid Medium, Proc. R. Soc, 83, 357-365, 1910.

Dal Maso, M., Kulmala, M., Lehtinen, K. E. J., Mäkelä, J. M., Aalto, P., and O'Dowd, C. D.: Condensation and coagulation sinks and formation of nucleation mode particles in coastal and boreal forest boundary layers, J. Geophys. Res., 107, 8097, doi:10.1029/2001JD001053 , 2002.

DeMott, P., Cziczo, D. J., Prenni, A., Murphy, D., Kreidenweis, S., Thomson, D., Borys, R., and Rogers, D.: Measurements of the concentration and composition of nuclei for cirrus formation, Proc. Nat. Acad. Sci., 100, 14655-14660, 2003.

Dentener, F., Kinne, S., Bond, T., Boucher, O., Cofala, J., Generoso, S., Ginoux, P., Gong, S., Hoelzemann, J. J., Ito, A., Marelli, L., Penner, J. E., Putaud, J.-P., Textor, C., Schulz, M., van der Werf, G. R., and Wilson, J.: Emissions of primary aerosol and precursor gases in the years 2000 and 1750 prescribed data-sets for AeroCom, Atmos. Chem. Phys., 6, 4321-4344, doi:10.5194/acp6-4321-2006, 2006.

Deshler, T., Hervig, M. E., Hofmann, D. J., Rosen, J. M., and Liley, J. B.: Thirty years of in situ stratospheric aerosol size distribution measurements from Laramie, Wyoming $\left(41^{\circ} \mathrm{N}\right)$, using balloon-borne instruments, J. Geophys. Res., 108, 4167, doi:10.1029/2002JD002514, 2003a.

Deshler, T., Larsen, N., Weissner, C., Schreiner, J., Mauersberger, K., Cairo, F., Adriani, A., Donfrancesco, G. D., Ovarlez, J., Ovarlez, H., Blum, U., Fricke, K., and Dörnbrack, A.: Large nitric acid particles at the top of an Arctic stratospheric cloud, J. Geophys. Res., 108, D01201, doi:10.1029/2003JD003479, 2003b.

Deshler, T., Anderson-Sprecher, R., Jäger, H., Barnes, J., Hofmann, D. J., Clemesha, B., Simonich, D., Osborn, M., Grainger, R. G., and Godin-Beekmann, S.: Trends in the nonvolcanic component of stratospheric aerosol over the period 1971-2004, J. Geophys. Res., 111, 4517, doi:10.1029/2005JD006089, 2006.

Dubovik, O., Smirnov, A., Holben, B. N., King, M. D., Kaufman, Y. J., Eck, T. F., and Slutsker, I.: Accuracy assessments of aerosol optical properties retrieved from Aerosol Robotic Network (AERONET) Sun and sky radiance measurements, J. Geophys. Res., 105, 9791-9806, 2000.

Dusek, U., Frank, G. P., Hildebrandt, L., Curtius, J., Schneider, J., Walter, S., Chand, D., Drewnick, F., Hings, S., Jung, D., Borrmann, S., and Andreae, M. O.: Size Matters More Than Chemistry for Cloud-Nucleating Ability of Aerosol Particles, Science, 312, 1375-1378, doi:10.1126/science.1125261, 2006.

Easter, R. C., Ghan, S. J., Zhang, Y., Saylor, R. D., Chapman, E. G., Laulainen, N. S., Abdul-Razzak, H., Leung, L. R., Bian, X., and Zaveri, R. A.: MIRAGE: Model description and evaluation of aerosols and trace gases, J. Geophys. Res., 109, D20210, doi:10.1029/2004JD004571, 2004.

Feichter, J., Kjellstrom, E., Rohde, H., Dentener, F., Lelieveld, J., and Roelofs, G. J.: Simulation of the tropospheric sulfur cycle in a global climate model, Atmos. Environ., 30, 1693-1707, 1996.

Fouquart, Y. and Bonnel, B.: Computations of solar heating of the earth's atmosphere: A new parameterisation, Beitr. Phys. Atmos., 53, 35-62, 1980.

Froyd, K. D., Murphy, D. M., Sanford, T. J., Thomson, D. S., Wilson, J. C., Pfister, L., and Lait, L.: Aerosol composition of the tropical upper troposphere, Atmos. Chem. Phys., 9, 4363-4385, doi:10.5194/acp-9-4363-2009, 2009.

Fu, R., Hu, Y. L., Wright, J. S., Jiang, J. H., Dickinson, R. E., Chen, M., Filipiak, M., Read, W. G., Waters, J. W., and Wu, D. L.: Short circuit of water vapor and polluted air to the global stratosphere by convective transport over the Tibetan Plateau, Proc. Nat. Acad. Sci., 103, 5664-5669, 2006.

Fuchs, N. A.: The mechanics of aerosols, Pergamon Press, Oxford, 1964.

Fueglistaler, S., Dessler, A. E., Dunkerton, T. J., Folkins, I., Fu, Q., and Mote, P. W.: Tropical tropopause layer., Rev. Geophys., 47, RG1004, doi:10.1029/2008RG000267, 2009.

Gelbard, F., Tambour, Y., and Seinfeld, J. H.: Sectional representations for simulating aerosol dynamics, J. Colloid Interface Sci., 76, 541-556, 1980.

Gerding, M., Baumgarten, G., Blum, U., Thayer, J. P., Fricke, K.H., Neuber, R., and Fiedler, J.: Observation of an unusual midstratospheric aerosol layer in the Arctic: possible sources and implications for polar vortex dynamics, Ann. Geophys., 21, 10571069, doi:10.5194/angeo-21-1057-2003, 2003.

Ghan, S. J. and Schwartz, S. E.: Aerosol properties and processes: A path from field and laboratory measurements to global climate models, B. Am. Meteorol. Soc., 88(7), 1059-1083, doi:10.1175/BAMS-88-7-1059, 2007.

Giauque, W. F., Hornung, E. W., Kunzler, J. E., and Rubin, T. R.: The thermodynamic properties of aqueous sulfuric acid solutions and hydrates from 15 to $300 \mathrm{~K}$, J. Am. Chem. Soc., 82, 62-70, 1960.

Gordley, L. L., Russell, J. M., Mickley, L. J., Frederick, J. E., Park, J. H., Stone, K. A., Beaver, G. M., McInemey, J. M., Deaver, L. E., Toon, G. C., Murcray, F. J., Blatherwick, R. D., Gunson, M. R., Abbatt, J. P. D., Mauldin, R. L., Mount, G. H., Sen, B., and Blavier, J.-F.: Validation of nitric oxide and nitrogen dioxide measurements made by the Halogen Occultation Experiment for UARS platform, J. Geophys. Res., 101, 10241-10266, 1996.

Grainger, R., Lambert, A., Rogers, C., Taylor, F., and Deshler, T.: Straospheric aerosol effective radius, surface area and volume estimated from infrared measurements, J. Geophys. Res., 100, 16507-16518, 1995.

Halmer, M. M., Schmincke, H.-U., and Graf, H.-F.: The annual volcanic gas input into the atmosphere, in particular into the stratosphere: A global data set for the past 100 years, J. Volcanol. Geotherm. Res., 115, 511-528, 2002.

Hamill, P., Toon, O. B., and Kiang, C. S.: Microphysical processes affecting stratospheric aerosol particles, J. Atmos. Sci. 34, 1104-1119, 1977.

Hamill, P., Jensen, E. J., Russel, P. B., and Bauman, J. J.: The life cycle of stratospheric aerosol particles, B. Am. Meteorol. Soc., 78, 1395-1410, 1997.

Heckendorn, P., Weisenstein, D., Fueglistaler, S., Luo, B. P., Rozanov, E., Schraner, M., Thomason, L. W., and Peter, T.: The impact of geoengineering aerosols on stratospheric temperature and ozone, Environ. Res. Lett., 4, 045108, doi:10.1088/1748- 
9326/4/4/045108, 2009.

Heitmann, H. and Arnold, F.: Composition measurements of troposheric ions, Nature, 306, 747-751, 1983.

Hines, C. O.: Doppler-spread parameterization of gravity wave momentum deposition in the middle atmosphere, 2, Broad and quasi-monochromatic spectra, and implementation, J. Atmos. Terr. Phys., 59, 387-400, 1997.

Hitchman, M. H., McKay, M., and Trepte, C. R.: A climatology of stratospheric aerosol, J. Geophys. Res., 99, 20689-20700, 1994.

Hofmann, D., Rosen, J., Harder, J., and Hereford, J.: Balloon-Borne Measurements of Aerosol, Condensation nuclei, and cloud particles in the stratosphere at McMurdo station, Antarctica, during the spring of 1987, J. Geophys. Res., 94, 11253-11269, 1989.

Hofmann, D., Barnes, J., O’Neill, M., Trudeau, M., and Neely, R.: Increase in background stratospheric aerosol observed with lidar at Mauna Loa Observatory and Boulder, Colorado, Geophys. Res. Lett., 36, L15808, doi:10.1029/2009GL039008, 2009.

Holton, J. R., Haynes, P. H., McIntyre, M. E., Douglass, A. R., Rood, R. R., and Pfister, L.: Stratospheric-tropospheric exchange, Rev. Geophys., 33, 403-439, 1995.

Hommel, R.: Die Variabilität von stratosphärischem HintergrundAerosol, Eine Untersuchung mit dem globalen sektionalen Aerosolmodell MAECHAM5-SAM2, Ph.D. thesis, Universität Hamburg, 2008.

Hommel, R. and Graf, H.-F.: Modelling the size distribution of geoengineered stratospheric aerosols, Atmos. Sci. Lett., 12, 168175, doi:10.1002/asl.285, 2010.

Horowitz, L. W., Walters, S., Mauzerall, D. L., Emmons, L. K., Rasch, P. J., Granier, C., Tie, X. X., Lamarque, J. F., Schultz, M. G., Orlando, G. S., and Brasseur, G. P.: A global simulation of tropospheric ozone and related tracers: Description and evaluation of MOZART, Version 2, J. Geophys. Res., 108, 4784, doi:10.1029/2002JD002853, 2003.

Hunton, D. E., Ballenthin, J. O., Borghetti, J. F., Federico, G. S., Miller, T. M., Thorn, W. F., Viggiano, A. A., Anderson, B. E., Cofer, W. R., McDougal, D. S., and Wey, C. C.: Chemical ionization mass spectrometric measurements of $\mathrm{SO}_{2}$ emissions from jet engines in flight and test chamber operations, J. Geophys. Res., 105, 26841-26855, 2000.

IPCC: Climate Change 2007: The Physical Science Basis. Contribution of Working Group I to the Fourth Assessment Report of the Intergovernmental Panel on Climate Change, edited by: Solomon, S., Qin, D., Manning, M., Chen, Z., Marquis, M., Averyt, K. B., Tignor, M., and Miller, H. L., Cambridge University Press, Cambridge, United Kingdom and New York, NY, USA, 996 pp., 2007.

Jacobson, M. Z.: Development and application of a new air pollution modelling system - Part II. Aerosol module structure and design, Atmos. Environ., 31, 131-144, 1997.

Jacobson, M. Z.: Fundamentals of atmospheric modeling, Cambridge University Press, Cambridge, 2nd Edn., 68 pp., 2005.

Jöckel, P., Sander, R., Kerkweg, A., Tost, H., and Lelieveld, J.: Technical Note: The Modular Earth Submodel System (MESSy) - a new approach towards Earth System Modeling, Atmos. Chem. Phys., 5, 433-444, doi:10.5194/acp-5-433-2005, 2005.

JPL/NASA: Chemical Kinetics and Photochemical Data for Use in Atmospheric Studies, JPL Publication 02-25, Evaluation No. 14, edited by: Sander, S. P., Friedl, R. R., Ravishankara, A. R., Golden, D. M., Kolb, C. E., Kurylo, M. J., Huie, R. E., Orkin,
V. L., Molina, M. J., Moortgat, G. K., and Finlayson-Pitts, B. J., NASA Jet Propulsion Laboratory, California Institute of Technology, Pasadena, California, 2003.

Kazil, J., Lovejoy, E. R., Jensen, E. J., and Hanson, D. R.: Is aerosol formation in cirrus clouds possible?, Atmos. Chem. Phys., 7, 1407-1413, doi:10.5194/acp-7-1407-2007, 2007.

Kent, G. S. and McCormick, M. P.: SAGE and SAM-II measurements of global stratospheric aerosol optical depth and mass loading, J. Geophys. Res., 84, 5303-5314, 1984.

Kent, G. S., Wang, P.-H., McCormick, M., and Skeens, K.: Multiyear Stratospheric Aerosol and Gas Experiment II measurements of upper tropospheric aerosol characteristics, J. Geophys. Res., 100, 13875-13899, 1995.

Kerminen, V.-M., Anttila, T., Lehtinen, K. E. J., and Kulmala, M.: Parametrization for atmospheric new-particle formation: application to a system involving sulfuric acid and condensable watersoluble organic vapors, Aerosol Sci. Tech., 38, 1001-1008, 2004.

Kettle, A. and Andreae, M.: Flux of the dimethylsulfide from the oceans: A comparison of updated data sets and flux models, J. Geophys. Res., 105, 26793-26808, 2000.

Kloster, S., Feichter, J., Maier-Reimer, E., Six, K. D., Stier, P., and Wetzel, P.: DMS cycle in the marine ocean-atmosphere system a global model study, Biogeosciences, 3, 29-51, doi:10.5194/bg3-29-2006, 2006.

Kokkola, H., Korhonen, H., Lehtinen, K. E. J., Makkonen, R., Asmi, A., Järvenoja, S., Anttila, T., Partanen, A.-I., Kulmala, M., Järvinen, H., Laaksonen, A., and Kerminen, V.-M.: SALSA - a Sectional Aerosol module for Large Scale Applications, Atmos. Chem. Phys., 8, 2469-2483, doi:10.5194/acp-8-2469-2008, 2008.

Kokkola, H., Hommel, R., Kazil, J., Niemeier, U., Partanen, A.-I., Feichter, J., and Timmreck, C.: Aerosol microphysics modules in the framework of the ECHAM5 climate model - intercomparison under stratospheric conditions, Geosci. Model Dev., 2, 97-112, doi:10.5194/gmd-2-97-2009, 2009.

Kritz, M. A.: Formation mechanism of stratospheric aerosol, Yale University, New Haven, Conn., 1975.

Kulmala, M. and Laaksonen, A.: Binary nucleation of water/sulfuric acid system: Comparison of classical theories with different $\mathrm{H}_{2} \mathrm{SO}_{4}$ saturation vapor pressures, J. Chem. Phys., 93, 696-701, 1990.

Lacis, A., Hansen, J., and Sato, M.: Climate forcing by stratospheric aerosols, Geophys. Res. Lett., 19, 1607-1610, 1992.

Lee, S.-H., Reeves, J. M., Wilson, J. C., Hunton, D. E., Viggiano, A. A., Miller, T. M., Ballenthin, J. O., and Lait, L. R.: Particle formation by ion nucleation in the upper troposphere and lower stratosphere, Science, 301, 1886-1889, 2003.

Lin, S. J. and Rood, R. B.: Multidimensional flux form semiLagrangian transport, Mon. Weather Rev., 124, 2046-2068, 1996.

Liu, X., Penner, J. E., and Herzog, M.: Global modeling of aerosol dynamics: Model description, evaluation, and interactions between sulfate and nonsulfate aerosols, J. Geophys. Res., 110, D18206, doi:10.1029/2004JD005674, 2005.

Ma, X. and von Salzen, K.: Dynamics of the sulphate aerosol size distribution on a global scale, J. Geophys. Res., 111, D08206, doi:10.1029/2005JD006620, 2006.

Makkonen, R., Asmi, A., Korhonen, H., Kokkola, H., Järvenoja, S., Risnen, P., Lehtinen, K. E. J., Laaksonen, A., Kerminen, V.- 
M., Järvinen, H., Lohmann, U., Bennartz, R., Feichter, J., and Kulmala, M.: Sensitivity of aerosol concentrations and cloud properties to nucleation and secondary organic distribution in ECHAM5-HAM global circulation model, Atmos. Chem. Phys., 9, 1747-1766, doi:10.5194/acp-9-1747-2009, 2009.

Manzini, E., Giorgetta, M. A., Esch, M., Kornblueh, L., and Roeckner, E.: The influence of sea surface temperatures on the northern winter stratosphere: Ensemble simulations with the MAECHAM5 model, J. Climate, 19, 3863-3881, 2006.

McCormick, M. P.: SAGE II: an overview, Adv. Space Res., 7, 219-226, 1987.

McDonald, J. E.: Saturation vapor pressures over supercooled water, J. Geophys. Res., 70, 1553-1554, 1965.

McIntyre, M. E. and Palmer, T. N.: The "surf zone" in the stratosphere, J. Atmos. Terr. Phys., 46, 825-849, 1984.

Meixner, F. X.: The vertical sulfur dioxide distribution at the tropopause level, J. Atmos. Chem., 2, 175-189, 1984.

Mills, M., Toon, O. B., and Solomon, S.: A 2D microphysical model of the polar stratospheric CN layer, Geophys. Res. Lett., 26, 1133-1136, 1999.

Mills, M., Toon, O., Vaida, V., Hintze, P., Kjaergaard, H., Schofield, D., and Robinson, T.: Photolysis of sulfuric acid vapor by visible light as a source of the polar stratospheric CN layer, J. Geophys. Res., 110, D08201, doi:10.1029/2004JD005519, 2005a.

Mills, M., Toon, O., Vaida, V., Hintze, P., Kjaergaard, H., Schofield, D., and Robinson, T.: Photolysis of sulfuric acid vapor by visible light as a source of the polar stratospheric CN layer, J. Geophys. Res., 110, D24208, doi:10.1029/2004JD005519, 2005b.

Mlawer, E. J., Taubman, S. J., Brown, P. D., Iacono, M. J., and Clough, S. A.: Radiative transfer for inhomogeneous atmospheres: RRTM, a validated correlated-k model for the longwave, J. Geophys. Res., 102, 16663-16682, 1997.

Möhler, O. and Arnold, F.: Gaseous sulfuric acid and sulfur dioxide measurements in the arctic troposphere and lower stratosphere: Implications for hydroxyl radical abundances, Geophys. Res. Lett., 19, 1763-1766, 1992.

Myhre, G., Stordal, F., Berglen, T., Sundet, J., and Isaksen, I.: Uncertainties in the Radiative Forcing Due to Sulfate Aerosols, J. Atmos. Sci., 61, 485-498, doi:10.1175/15200469(2004)061<0485:UITRFD>2.0.CO;2, 2004.

Pan, W., Tatang, M., McRae, G., and Prinn, R.: Uncertainty analysis of indirect radiative forcing by anthropogenic sulfate aerosols, J. Geophys. Res., 103, 3815-3823, 1998.

PARTS: Particles in the upper troposphere and lower stratosphere and their role in the climate system (PARTS): Detailed report, related to overall project duration, edited by: Graf, H.-F., European Commission, European Research Framework 5, available at: http://parts.dkrz.de, 2004.

Penner, J., Andreae, M., Annegarn, H., Barrie, L., Feichter, J., Hegg, D., Jayaraman, A., Leaitch, R., Murphy, D., Nganga, J., and Pitari, G.: Climate Change 2001: The Scientific Basis, Chapter 5: Aerosols, their Direct and Indirect Effects., IPCC Third Assessment Report, Cambridge University Press, Cambridge, United Kingdom and New York, NY, USA, 996 pp., 2001.

Pham, M., Muller, J.-F., Brasseur, G., Granier, C., and Megie, G.: A three-dimensional study of the tropospheric sulfur cycle, J. Geophys. Res., 100, 26061-26092, 1995.

Pinnick, R. G., Rosen, J. M., and Hofmann, D. J.: Stratospheric aerosol measurements, 3, Optical model calculations, J. Atmos.
Sci., 33, 304-314, 1976.

Pitari, G., Mancini, E., Rizi, V., and Shindell, D. T.: Impact of future climate and emission changes on stratospheric aerosols and ozone, J. Atmos. Sci., 59, 414-440, 2002.

Rasch, P. J., Crutzen, P. J., and Coleman, D. B.: Exploring the geoengineering of climate using stratospheric sulfate aerosols: The role of particle size, Geophys. Res. Lett., 35, L02809, doi:10.1029/2007GL032179, 2008.

Reiner, T. and Arnold, F.: Stratospheric $\mathrm{SO}_{3}$ : Upper limits inferred from ion composition measurements - Implications for $\mathrm{H}_{2} \mathrm{SO}_{4}$ and aerosol formation, Geophys. Res. Lett., 24, 17511754, 1997.

Rinsland, C. P., Gunson, M. R., Ko, M. K. W., Weisenstein, D. W., Zander, R., Abrams, M. C., Goldman, A., Sze, N. D., and Yue, G. K.: $\mathrm{H}_{2} \mathrm{SO}_{4}$ photolysis: A source of sulfur dioxide in the upper stratosphere, Geophys. Res. Lett., 22, 1109-1112, 1995.

Robock, A.: Volcanic eruptions and climate, Rev. Geophys., 38, 191-219, 2000.

Roche, A. E., Kumer, J. B., Mergenthaler, J. L., Ely, G. A., Uplinger, W. G., Potter, J. F., James, T. C., and Sterritt, L. W.: The Cryogenic Limb Array Etalon Spectrometer (CLAES) on UARS: Experiment Description and Performance, J. Geophys. Res., 98, 10763-10775, doi:10.1029/93JD00800, 1993.

Roeckner, E., Baueml, G., Bonaventura, L., Brokopf, R., Esch, M., Giorgetta, M., Hagemann, S., Kirchner, I., Kornblueh, L., Manzini, E., Rhodin, A., Schlese, U., Schulzweida, U., and Tompkins, A.: The atmospheric general circulation model ECHAM5 - Part I, MPI Report No. 349, 2003.

Rose, W., Gu, Y., Watson, I., Yu, T., Bluth, G., Prata, A., Krueger, A., Krotkov, N., Carn, S., Fromm, M., Hunton, D., Ernst, G., Viggiano, A., Miller, T., Ballentin, J., Reeves, J., Wilson, J., Anderson, B., and Flittner, D.: The February-March 2000 eruption of Hekla, Iceland from a satellite perspective, in: AGU Geophysical Monograph 139: Volcanism and the Earth's Atmosphere, ISBN 0-87590-998-1, edited by: Robock, A. and Oppenheimer, C., John Wiley and Sons, 107-132, 2003.

Russell, P. B., Livingston, J. M., Pueschel, R. F., Pollack, J. B., Brooks, S., Hamill, P., Hughes, J., Thomason, L., Stowe, L., Deshler, T., and Dutton, E.: Global to microscale evolution of the Pinatubo volcanic aerosol, derived from diverse measurements and analyses, J. Geophys. Res., 101, 18745-18763, 1996.

Schlager, H. and Arnold, F.: Balloon-borne composition measurements of stratospheric negative ions and inferred sulfuric acid vapor abundances during the MAP/GLOBUS 1983 campaign, Planet. Space Sci., 35, 693-701, 1987.

Seinfeld, J. H. and Pandis, S. N.: Atmospheric chemistry and physics: From air pollution to climate change, WileyInterscience, New York, 1998.

Sheridan, P. J., Brock, C. A., and Wilson, J. C.: Aerosol particles in the upper troposphere and lower stratosphere: Elemental composition and morphology of individual particles in northern midlatitudes, Geophys. Res. Lett., 21, 2587-2590, 1994.

Spalding, D. B.: A novel finite-difference formulation for differential expressions involving both first and second derivatives, Int. J. Num. Methods, 4, 551-559, 1972.

SPARC/ASAP: WMO/SPARC Scientific Assessment of Stratospheric Aerosol Properties (ASAP), WCRP-124 WMO/TDNo. 1295, SPARC Report No. 4, edited by: Thomason, L. and Peter, Th., WMO, 2006. 
Spracklen, D. V., Pringle, K. J., Carslaw, K. S., Chipperfield, M. P., and Mann, G. W.: A global off-line model of sizeresolved aerosol microphysics: I. Model development and prediction of aerosol properties, Atmos. Chem. Phys., 5, 222702252, doi:10.5194/acp-5-2227-2005, 2005.

Steele, H., Lumpe, J., Turco, R., Bevilacqua, R., and Massie, S.: Retrieval of aerosol surface area and volume densities from extinction measurements: Application to POAM II and SAGE II, J. Geophys. Res., 104, 9325-9336, 1999.

Steele, H. M. and Hamill, P.: Effects of temperature and humidity on the growth and optical properties of sulfuric acid-water droplets in the stratosphere, J. Aerosol Sci., 12, 517-528, 1981.

Steil, B., Brühl, C., Manzini, E., Crutzen, P. J., Lelieveld, J., Rasch, P. J., Roeckner, E., and Krueger, K.: A new interactive chemistry-climate model, 1 . Present day climatology and interannual variability of the middle atmosphere using the model and 9 years of HALOE/UARS data., J. Geophys. Res., 108, 4290, doi:10.1029/2002JD002971, 2003.

Stenchikov, G., Robock, A., Ramaswamy, V., Schwartzkopf, M. D., Hamilton, K., and Ramachandran, S.: Arctic Oscillation response to the 1991 Mount Pinatubo eruption: Effects of volcanic aerosols and ozone depletion, J. Geophys. Res, 107, 1-16, 2002.

Stenchikov, G., Hamilton, K., Stouffer, R. J., Robock, A., Ramaswamy, V., Santer, B., and Graf, H.-F.: Arctic Oscillation response to volcanic eruptions in the IPCC AR4 climate models, J. Geophys. Res., 111, 1-16, doi:10.1029/2005JD006286, 2006.

Stier, P., Feichter, J., Kinne, S., Kloster, S., Vignati, E., Wilson, J., Ganzeveld, L., Tegen, I., Werner, M., Balkanski, Y., Schulz, M., Boucher, O., Minikin, A., and Petzold, A.: The aerosolclimate model ECHAM5-HAM, Atmos. Chem. Phys., 5, 11251156, doi:10.5194/acp-5-1125-2005, 2005.

Takigawa, M., Takahashi, M., and Akiyoshi, H.: Simulation of stratospheric sulfate aerosols using a Center for Climate System Research/National Institute for Environmental Studies atmospheric GCM with coupled chemistry 1 . Nonvolcanic simulation, J. Geophys. Res., 107, 4610, doi:10.1029/2001JD001007, 2002.

Tanre, D., Geleyn, J.-F., and Slingo, J. M.: First results of the introduction of an advanced aerosol-radiation interaction in the ECMWF low resolution global model, in Aerosols and Their Climatic Effects, edited by: Gerber, H. and Deepak, A., Hampton, VA, 133-177, 1984.

Thomas, M. A., Timmreck, C., Giorgetta, M. A., Graf, H.-F., and Stenchikov, G.: Simulation of the climate impact of Mt. Pinatubo eruption using ECHAM5 - Part 1: Sensitivity to the modes of atmospheric circulation and boundary conditions, Atmos. Chem. Phys., 9, 757-769, doi:10.5194/acp-9-757-2009, 2009.

Thomason, L. W., Poole, L. R., and Deshler, T.: A global climatology of stratospheric aerosol surface area density deduced from Stratospheric Aerosol and Gas Experiments II measurements: 1984-1994, J. Geophys. Res., 102, 8967-8976, 1997.

Thomason, L. W., Burton, S. P., Luo, B.-P., and Peter, T.: SAGE II measurements of stratospheric aerosol properties at non-volcanic levels, Atmos. Chem. Phys., 8, 983-995, doi:10.5194/acp-8-9832008, 2008.

Timmreck, C.: Three-dimensional simulation of stratospheric background aerosol: First results of a multiannual general circulation model simulation, J. Geophys. Res., 106, 28313-28332, 2001.

Timmreck, C. and Graf, H.-F.: A microphysical model to simulate the development of stratospheric aerosol in a GCM, Meteorol.
Z., 9, 263-282, 2000.

Timmreck, C., Graf, H.-F., and Kirchner, I.: A one and half year interactive MA/ECHAM4 simulation of Mount Pinatubo Aerosol, J. Geophys. Res., 104, 9337-9360, 1999.

Tolbert, M. A.: Sulfate aerosols and polar stratospheric cloud formation, Science, 264, 527-528, 1994.

Toon, O. B., Turco, R. P., Hamill, P., Kiang, C. S., and Whitten, R. C.: A one-dimensional model describing aerosol formation and evolution in the stratosphere: II. Sensitivity studies and comparision with observations, J. Atmos. Sci., 36, 718-736, 1979.

Toon, O. B., Turco, R. P., Westphal, D., Malone, R., and Liu, M. S.: A multidimensional model for aerosols: Description of computational analogs, J. Atmos. Sci., 45, 2123-2143, 1988.

Trepte, C. R. and Hitchman, M. H.: Tropical stratospheric circulation deduced from satellite aerosol data, Nature, 355, 626-628, 1992.

Tsang, T. H. and Brock, J. R.: Simulation of condensation aerosol growth by condensation and evaporation, Aerosol Sci. Tech., 2, 311-320, 1983.

Turco, R. P., Hamill, P., Toon, O. B., Whitten, R. C., and Kiang, C. S.: A one-dimensional model describing aerosol formation and evolution in the stratosphere: I. physical processes and mathematical analogs, J. Atmos. Sci., 36, 699-717, 1979.

Turco, R. P., Toon, O. B., Hamill, P., and Whitten, R. C.: Effects of meteoric debris on stratospheric aerosols and gases, J. Geophys. Res., 86, 1113-1128, 1981.

Vaida, V., Kjaergaard, H. G., Hintze, P. E., and Donaldson, D. J.: Photolysis of sulfuric acid vapor by visible solar radiation, Science, 299, 1566-1568, 2003.

Vehkamäki, H., Kulmala, M., Napari, I., Lehtinen, K. E. J., Timmreck, C., Noppel, M., and Laaksonen, A.: An improved parameterization for sulfuric acid water nucleation rates for tropospheric and stratospheric conditions, J. Geophys. Res., 107, 4622-4632, 2002.

Viggiano, A. A. and Arnold, F.: Extended sulfuric acid vapor concentration measurements in the stratosphere, Geophys. Res. Lett., 8, 583-586, 1981.

Waugh, D. W., Plumb, R. A., Newman, P. A., Schoeberl, M. R., Lait, L. R., Loewenstein, M., Podolske, J. R., Elkins, J. W., and Chan, K. R.: Fine-scale, poleward transport of tropical air during AASE 2, Geophys. Res. Lett., 21, 2603-2606, 1994.

Weisenstein, D. K., Yue, G. K., Ko, M. K. W., Sze, N.-D., Rodriguez, J. M., and Scott, C. J.: A two-dimensional model of sulfur species and aerosols, J. Geophys. Res., 102, 13019-13035, 1997.

Weisenstein, D. K., Penner, J. E., Herzog, M., and Liu, X.: Global 2-D intercomparison of sectional and modal aerosol modules, Atmos. Chem. Phys., 7, 2339-2355, doi:10.5194/acp-7-23392007, 2007.

Wurl, D., Grainger, R. G., McDonald, A. J., and Deshler, T.: Optimal estimation retrieval of aerosol microphysical properties from SAGE II satellite observations in the volcanically unperturbed lower stratosphere, Atmos. Chem. Phys., 10, 4295-4317, doi:10.5194/acp-10-4295-2010, 2010.

Yue, G., Poole, L., Wang, P.-H., and Chiou, E.: Stratospheric aerosol acidity, density, and refractive index deduced from SAGE II and NMC temperature data, J. Geophys. Res., 99, 3727-3738, 1994.

Zhang, Y., Easter, R. C., Ghan, S. J., and Abdul-Razzak, 
H.: Impact of aerosol size representation on modelling aerosol-cloud interactions, J. Geophys. Res., 107, 4558, doi:10.1029/2001JD001549, 2002.
Zhao, J. and Turco, R. P.: Nucleation simulation in the wake of a jet aircraft in stratospheric flight, J. Atmos. Sci., 26, 779-795, 1995. 